Portland State University

PDXScholar

TREC Final Reports

Transportation Research and Education Center

(TREC)

6-2017

\title{
Measuring the Impacts of Social Media on Advancing Public Transit
}

Jenny H. Liu

Portland State University, jenny.liu@pdx.edu

Xuegang Ban

Rensselaer Polytechnic Institute

O. A. Elrahman

Rensselaer Polytechnic Institute

Follow this and additional works at: https://pdxscholar.library.pdx.edu/trec_reports

Part of the Transportation Commons, Urban Studies Commons, and the Urban Studies and Planning Commons

Let us know how access to this document benefits you.

\section{Recommended Citation}

Liu, Jenny Hsing-I, Xuegang (Jeff) Ban, and Elrahman, (Sam) O.A. Measuring the Impacts of Social Media on Advancing Public Transit. NITC-RR-654. Portland, OR: Transportation Research and Education Center (TREC), 2017. https://doi.org/10.15760/trec.174

This Report is brought to you for free and open access. It has been accepted for inclusion in TREC Final Reports by an authorized administrator of PDXScholar. Please contact us if we can make this document more accessible: pdxscholar@pdx.edu. 


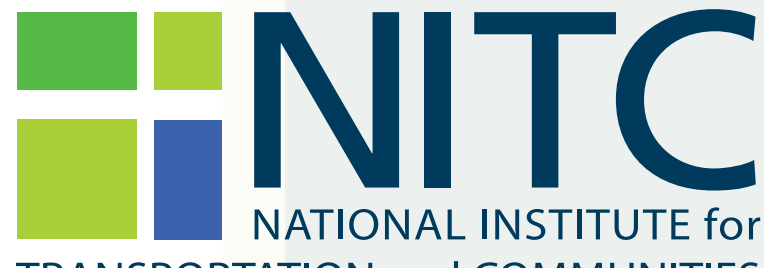

TRANSPORTATION and COMMUNITIES

FINAL REPORT

Measuring the Impacts of Social Media on Advancing Public Transit

NITC-RR-654 June 2017

NITC is a U.S. Department of Transportation national university transportation center.

HI! TREC 



\title{
MEASURING THE IMPACTS OF SOCIAL MEDIA ON ADVANCING PUBLIC TRANSIT
}

\section{FINAL REPORT}

NITC-RR-654

\author{
by \\ Jenny Hsing-I Liu \\ Portland State University \\ Xuegang (Jeff) Ban \\ Rensselaer Polytechnic Institute \\ Center for Infrastructure, Transportation and the Environment (CITE) \\ O.A. (Sam) Elrahman \\ Rensselaer Polytechnic Institute \\ Center for Infrastructure, Transportation and the Environment (CITE) \\ for
}

National Institute for Transportation and Communities (NITC)

P.O. Box 751

Portland, OR 97207
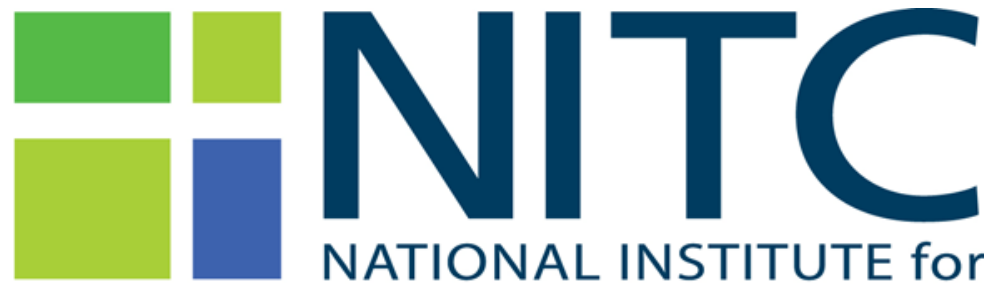

TRANSPORTATION and COMMUNITIES

June 2016 



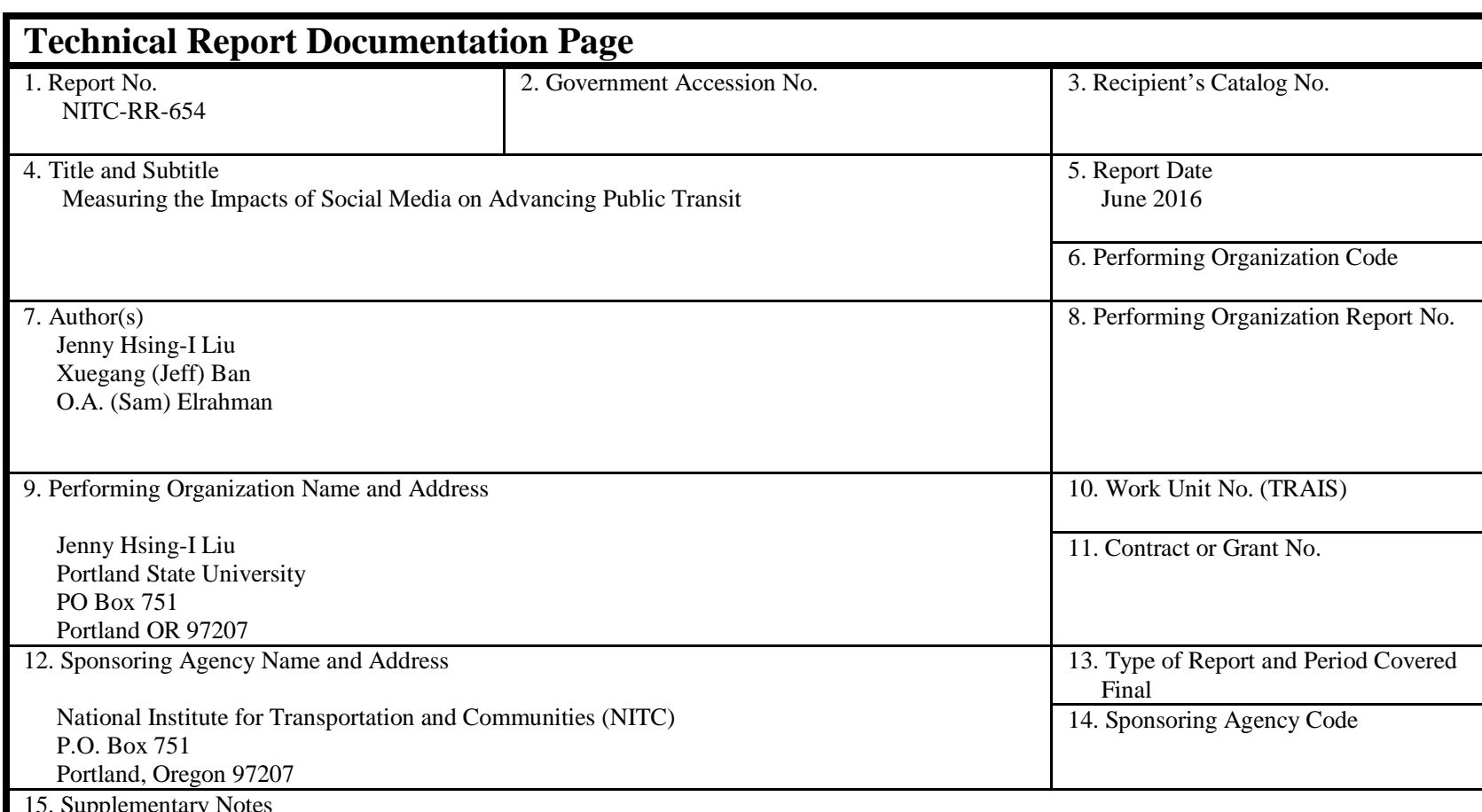

15. Supplementary Notes

\section{Abstract}

This project is a collaboration between Portland State University (PSU) and the Center for Infrastructure Transportation \& Environment (CITE) at Rensselaer Polytechnic Institute seeking to develop performance measures for assessing the impacts of social media on promoting public transit. Revolutionary changes have occurred in the communication landscape, and there has been a rapid diffusion of social media use as a means of communicating transit information to the public. Significant resources are being directed to the use of social media in communication, yet little effort exists that measures the impacts of these popular vehicles of communication. Rarely studied is the role of social media in achieving the overarching goals of advancing the mission of transit agencies through increasing recruitment and retention of transit riders; increasing resources and customer satisfaction; addressing system issues, performance efficiency and effectiveness; and improving employee productivity and morale. There is a need to measure the impacts of social media and account for the cost effectiveness of its wide use as a means of communication in public transit agencies. This research intends to extend understanding about whether investments in social media tools effectively achieve their intended purposes.

The goal of this project is to identify social media-related measures for public transit agencies that can comprehensively capture the impacts of social media use on agency performance. This project will rely on a review of the research and practice literature to document findings in other fields on performance measures used to assess the impacts of social media. Best practices will be identified. A survey of a random sample of public transit agencies nationwide will target identifying performance measures currently used to document impacts. Gaps will be identified. Investigators will compare and contrast measures used in transit agencies and other fields and identify a list of performance measures that are most effective for transit agencies.
17. Key Words
18. Distribution Statement
No restrictions. Copies available from NITC: www.nitc.us

19. Security Classification (of this report)

20. Security Classification (of this page)
Unclassified

21. No. of Pages
56

22. Price

Unclassified

Unclassified 



\section{ACKNOWLEDGEMENTS}

This project was funded by the National Institute for Transportation and Communities (NITC).

\section{DISCLAIMER}

The contents of this report reflect the views of the authors, who are solely responsible for the facts and the accuracy of the material and information presented herein. This document is disseminated under the sponsorship of the U.S. Department of Transportation University Transportation Centers Program, Portland State University and the Center for Infrastructure, Transportation and the Environment (CITE) at Rensselaer Polytechnic Institute in the interest of information exchange. The U.S. Government assumes no liability for the contents or use thereof. The contents do not necessarily reflect the official views of the U.S. Government, Portland State University or CITE at Rensselaer Polytechnic Institute. This report does not constitute a standard, specification, or regulation.

\section{RECOMMENDED CITATION}

Liu, Jenny Hsing-I, Xuegang (Jeff) Ban, and O.A. (Sam) Elrahman. Measuring the Impacts of Social Media on Advancing Public Transit. NITC-RR-654. Portland, OR: Transportation Research and Education Center (TREC), 2017. 


\section{TABLE OF CONTENTS}

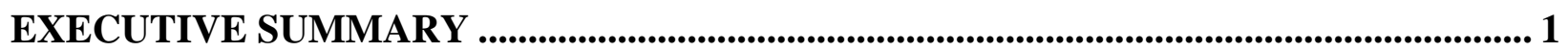

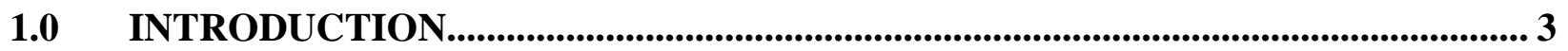

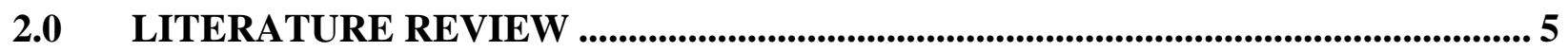

2.1 UNDERSANDING SOCIAL MEDIA AND THE USERS …………........................... 5

2.2 USE OF SOCIAL MEDIA PROGRAMS AND PERFORMANCE METRICS IN THE TRANSPORTATION INDUSTRY …………………............................................... 7

2.2.1 Current Use and Goals of Social Media Programs ..................................................... 7

2.2.2 The Benefits and Effectiveness of Using Social Media Programs .............................. 7

2.2.3 Challenges and Practices of Using Social Media Programs ........................................... 8

2.2.4 Social Media Performance Metrics.......................................................................... 9

2.3 USE OF SOCIAL MEDIA PROGRAMS AND PERFORMANCE METRICS IN OTHER SECTORS........................................................................................... 10

2.3.1 Current Usage and Purposes of Social Media....................................................... 10

2.3.2 Performance Metrics of Measuring Social Media ....................................................... 11

2.3.3 Supplementary Lessons from Other Sectors................................................................ 13

3.0 HOW AGENCIES USE SOCIAL MEDIA - SURVEY RESULTS.............................. 15

3.1 TRANSIT AGENCIES' SURVEY ........................................................................... 15

3.2 TRANSIT AGENCIES' RESPONSES ……………................................................. 16

3.2.1 Responding Agencies................................................................................. 16

3.2.2 Socials Media Usage and Measurement in Public Transit Agencies.......................... 16

3.2.3 Social Media Usage Across Regions and Agencies ..................................................... 19

3.2.4 Factors Influencing Social Media Usage in Public Transit Agencies......................... 22

3.3 HEALTHCARE ORGANIZATIONS' SURVEY RESPONSES...................................... 25

3.4 HIGHER-EDUCATION ORGANIZATIONS’ SURVEY RESPONSES.......................... 26

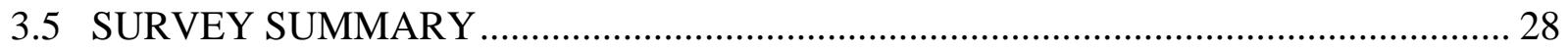

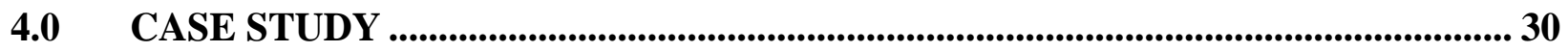

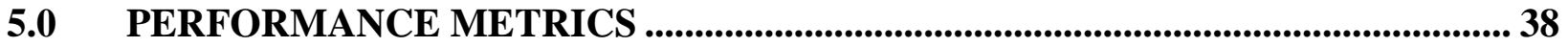

5.1 LESSONS FROM CURRENT SOCIAL MEDIA USAGE ………................................ 38

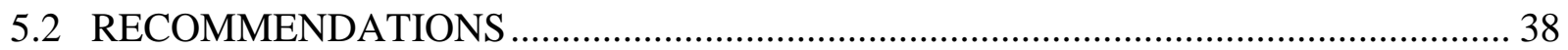

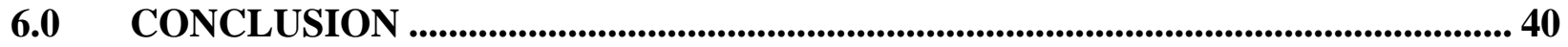

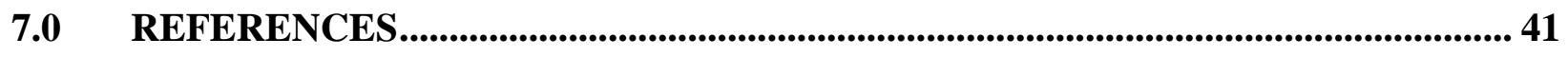

8.0 APPENDIX - SURVEY INSTRUMENT .............................................................. 45 


\section{LIST OF TABLES}

Table 1. City and Agency Attributes of Responding Public Transit Agencies .......................... 16

Table 2. Social Media Usage Survey Results by Region.......................................................... 21

Table 3. Regression Model Results with Standardized Coefficients (t-statistic) for Social Media

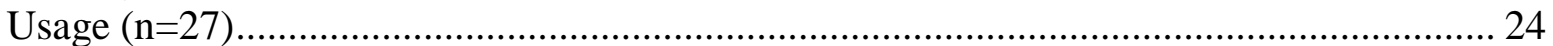

Table 4. List of Top Transit Agencies' Social Media Presence on Official Website (as of May, 2016)

\section{LIST OF FIGURES}

Figure 1. Social Networking Site Use Trend ................................................................... 3

Figure 2. Percentage of Internet Users Who Use Social Networking Sites................................. 6

Figure 3. Social Media Structure and Major Platforms Among Transit Agencies ...................... 17

Figure 4. Purpose and Measurement of Social Media Usage in Transit Agencies...................... 18

Figure 5. Correlation Matrix of Social Media Usage and City/Agency Attributes $(n=27)$.......... 20

Figure 6. Social Media Program Components and Platforms.................................................. 25

Figure 7. Purpose and Measurement of Social Media Usage in Healthcare Organizations ......... 26

Figure 8. Social Media Program Components and Platforms.................................................. 27

Figure 9. Purpose and Measurement of Social Media Usage in Healthcare Organizations ......... 28

Figure 10. Distribution of Researched Top Transit Agencies ............................................... 30

Figure 11. Examples of Social Media Presence Notation....................................................... 35

Figure 12. Word Cloud of Social Media Policy (Upper left: Sound Transit; Upper right: LYNX;

Lower left: WMATA; Lower right: Miami Dade) ....................................................... 36 


\section{EXECUTIVE SUMMARY}

Social media has been gaining prominence in public transit agencies for their communication strategies and daily management. In 2009, 66\% of government agencies used some form of social networking, and 65\% of them used more than one tool (Human Capital Institute, 2010). Fifty-four percent of public transportation agencies use Facebook, 51\% use Twitter and 37\% use YouTube according to a report published by the Urban Transportation Monitor in 2011. However, a review of the academic and practice literature shows very limited evidence of available performance metrics that can be applied to measure the effectiveness and efficiency of these efforts. This study focuses on social media within public transit agencies, particularly due to the frequency and intensity of information exchanges and interactions between these agencies and the population they serve on a daily basis (e.g., transit system alerts, live transit arrival information, service disruptions, etc.). Our objective is to better understand recent trends in social media usage in public transit agencies, to examine which agencies use what kind of social media programs for what purposes, and how they measure and evaluate their programs. Furthermore, we explore the types of performance measures that may be valuable in assessing whether investments in social media tools effectively achieve their intended purposes.

Based on a literature review and preliminary examination of social media usage and measurement at public transit agencies, the research team designed and conducted an online survey of top transit agencies around the country in 2015. Based on survey responses from 27 transit agencies, we found that social media is most used to communicate timely service information and obtain feedback from transit riders. Over $40 \%$ of responding public transportation agencies have full-time staff exclusively dedicated to social media work, with an average of 1.33 full-time equivalent staff members. In many agencies (59\%), while there is not personnel dedicated exclusively to social media communications, the responsibility is spread amongst multiple staff members who have other job responsibilities, averaging around five employees.

Although most agencies indicated that they have some structure in their social media program (e.g., having strategies, target audiences, and ways to measure the program), few agencies have clearly defined goals and objectives associated with their social media program. Performance is currently measured through simple counts of subscribers or the frequency of re-posts or "likes,"but agencies place high value on additional less-frequently used metrics that measure perceptions, sentiments and overall satisfaction through social media platforms, as shown in the figure below. We additionally collected survey responses from smaller samples of healthcare and higher-education organizations to identify social media performance metrics currently in use in these fields that may be adaptable to public transportation. 


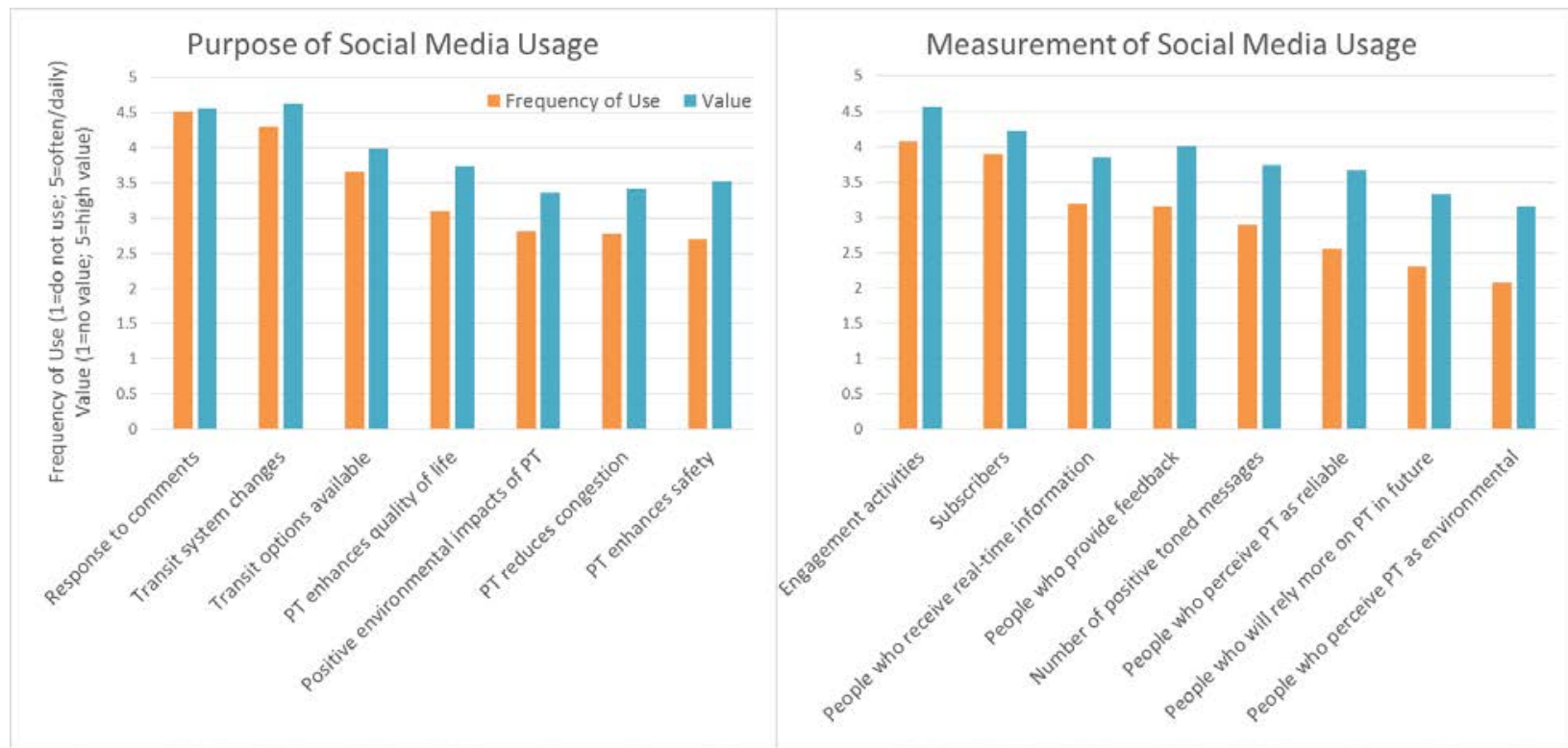

Figure E1. Purpose and Measurement of Social Media Usage in Transit Agencies

Several multivariate regression models were constructed to determine the factors that determine social media usage and measurement in public transit agencies. We found that public transit service consumption or usage and the level of transit service provision are the most significant determinants of public transportation agencies' social media programming and labor resource investments. In contrast, the measurements of social media usage and outcomes are determined more by city attributes and demographic characteristics, such as age composition and geographic region.

To cross-validate our survey and model findings, we further conducted a case study assessment of the 52 transit agency websites to evaluate their social media presence, documents and policy descriptions (including goals, objectives or strategies), and available performance measurements. We found that although social media is widely mentioned in agencies' communications, public participation or marketing plans, few agencies have explicit documentation or policy documents that specifically provide guidance on social media program usage, goals, objectives or performance measurement plans.

Finally, based on the comprehensive literature review, survey results, estimation models and case studies conducted, we propose a conceptual performance metrics framework for developing constructive social media program metrics that focus on reach, insights, engagement and efficiency going forward. As a combination of quantitative and qualitative data, this framework will work best when it is strongly connected with a public transit agency's mission, goals and objectives associated with the social media programs. 


\subsection{INTRODUCTION}

Revolutionary changes have occurred in the communications landscape, and there has been a rapid diffusion of social media use as a means of communicating transit information to the public. Significant resources are being directed to the use of social media in communication, yet little effort exists that measures the impacts of these popular vehicles of communication. Rarely studied is the role of social media in achieving the overarching goals of advancing the mission of transit agencies through increasing recruitment and retention of transit riders; increasing resources and customer satisfaction; addressing system issues, performance efficiency and effectiveness; and improving employee productivity and morale. There is a need to measure the impacts of social media and account for the cost effectiveness of its wide use as a means of communication in public transit agencies. This project is designed to extend understanding about whether investments in social media tools effectively achieve their intended purposes through both quantitative and qualitative performance measures.

In 2009, 66\% of government agencies used some form of social networking, and $65 \%$ of them used more than one tool (Human Capital Institute, 2010). Fifty-four percent of public transportation agencies used Facebook, 51\% used Twitter and 37\% used YouTube (Urban Transportation Monitor, 2011). Social media was used by public transportation agencies to communicate brief messages, service updates, meeting notices, project updates, agency promotion, service tutorials, stories and testimonials. They were also used for community building and branding, networking and recruiting purposes, and in-depth discussions. Reasons cited by agencies for using social media included provision of timely updates, communication of public information, citizen engagement, employee recognition and entertainment (TCRP Synthesis 99, 2012). In addition, a growing percentage of the audience that transit agencies are trying to reach is engaged in the social networking, shown in the figure on the right.

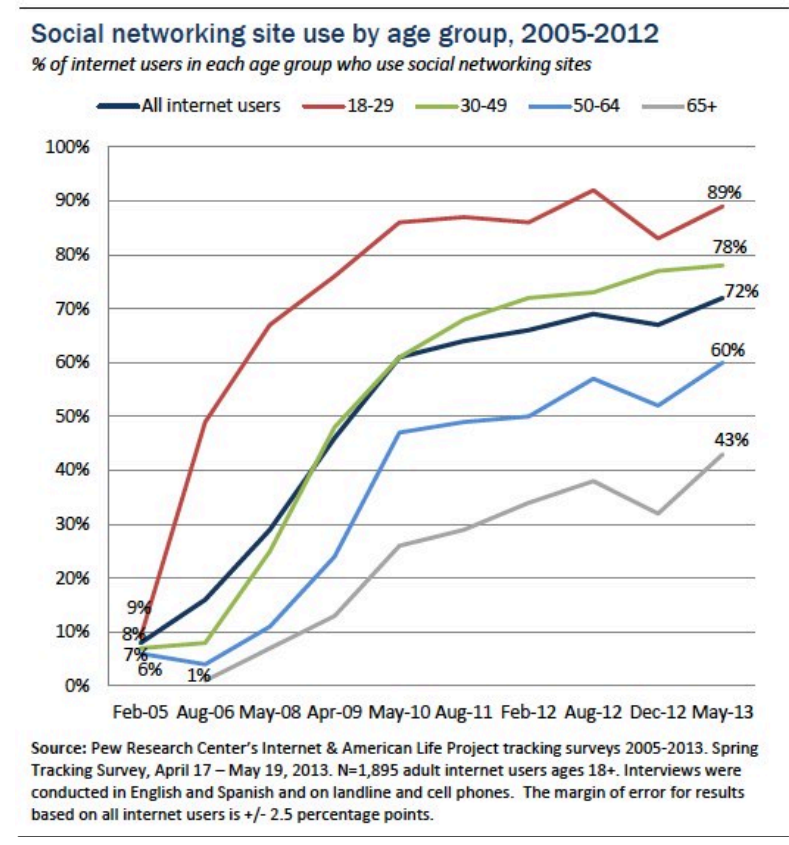

Figure 1. Social Networking Site Use Trend Source: Brenner and Smith (2013) 
Social media, however, represents a significant investment of staff resources. Maintaining the sites, responding to users' comments and constantly updating the public face of the agency on social media requires dedication of staff time, which tended to be more extensive for large agencies located in urban areas. More than $50 \%$ of agencies surveyed in a 2011 study allocated a minimum of 40 hours per month to social media, while $23 \%$ devoted more than 80 hours per month. There is a general consensus that social media is "worth trying." However, when Chin et al. (2012) of the American Public Transportation Association surveyed transportation providers across the country, they found that although $94 \%$ of those surveyed used some form of social media, only $28 \%$ had a social media plan or strategy prior to implementation.

The lack for social media metrics, however, is undeniable. Most past and ongoing research has focused on the marketing aspects of social media (TCRP Synthesis 105, 2013; Stambaugh, 2013); case studies of social media in certain agencies such as New York's Metropolitan Transportation Authority or San Francisco's Bay Area Rapid Transit (TCRP, 2012) or identifying users of social media (Birdsall, 2013). Additional research is needed to systematically understand the effectiveness of social media activities in public transportation, and the cost and benefits of social media. While most agencies currently measure effectiveness through built-in metrics such as number of "friends and followers" or "likes," or by using Google analytics, this information does not go far enough in justifying the investment of human resources in social media (TCRP, 2012). There is a need to identify metrics and performance indicators that can help transit agencies account for the effectiveness of social media in achieving agency communication objectives.

This research aims to fill this gap by first identifying and synthesizing the relevant research and practice literature on the usage of social media as well as performance measurements of social media in the public realm in Section 2.0. Then, utilizing a survey of top transit agencies in the nation, as well as select healthcare and higher-education organizations, we analyze how agencies are using social media in the next section. Through this survey, we gain a better understanding of the types of communications and messages that are sent through social media as well as the types of measurements that are currently used and are potentially valuable for the agencies. In Section 4.0, we conduct a case study assessment of public websites of top transit agencies to gauge their social media presence; available policy descriptions and documentation; incorporation with other agency plans (i.e., strategic plan, communications plan, public participation/involvement plan, and marketing plan); performance measurements; and additional experiences. Finally, we propose a social media performance measurement framework in Section 5.0 and conclude in Section 6.0. 


\subsection{LITERATURE REVIEW}

Research shows a growing number of public transportation agencies use a variety of social media programs to inform and engage riders in dialogue. The wide usage of social media in transit agencies enables them to provide timely transit information, broaden ways to communicate and engage with customers, and enhance awareness and perception of transit agencies. However, there is a significant lack of information on how effective and efficiently resources are being used in social media programs. The existing metrics mainly focus on collecting data, with little analysis and few meaningful guidelines for future social media development. Recently, more advanced approaches and methods, such as data mining and sentiment analysis, have been constructed to understand and evaluate social media usage. This provides guidelines for the future on how to develop interactive and insightful social media strategies and measures for effective use. There is an undeniable lack of information on metrics to measure the effectiveness of social media, which is the main focus of this project.

A similar, more advanced trend of social media use is happening among other sectors, including healthcare and higher education, among others. In other sectors, organizations utilize social media for similar purpose as transit agencies, which are to inform, communicate and engage target audiences. In the healthcare industry, research indicates well-designed performance metrics that are categorized as reach, exposure, insights and engagement to evaluate social media development rather than simply collecting statistical numbers. In the higher-education sector, there are practices of developing quantitative and qualitative methods to measure the success of social media programs through the amount of audience and quality of interaction. However, there remains concern over the investment returns of social media programs in those sectors.

With widespread use of social media in public agencies, four factors of effective use of social media are presented: cultural shift from traditional social media interactions; public engagement in an open manner; a deeper cost-benefit and risk analysis; and tighter connections of social media to organizations' missions and goals. In addition, related policies are required for social media legal, security and privacy concerns.

\subsection{UNDERSANDING SOCIAL MEDIA AND THE USERS}

Given the wide application of the internet, people increasingly transform from traditional communication means to use internet sites, apps and blogs to post and share ideas and content. Social media, as a group of platforms, provides a means for sharing information and interests, and participating in conversations. 
There are many social media platforms, among which Facebook, Twitter and YouTube are the most popular, according to different rankings and user evaluations. However, there are much more diverse platforms spanning across social bookmarking, micromedia, niche network, video aggregation and social curation (Bartlett \& Miller, 2013). For example, LinkedIn is the largest professional network in terms of users; Tumblr and Flickr serve specific niche communities with similar interests. Social media accounts for a large amount of time spent online. For example, Facebook users spend 9.7 billion minutes on the site, share four billion pieces of content and upload 250 million photos on an average day (Bartlett \& Miller, 2013).

Social media is widely used by people with different demographic characteristics and professional statuses. In terms of the demographic characteristics of the users, studies found that the younger generation is the dominant demographic within the realm of social media (Chou, Hunt, Beckjord, Moser \& Hesse, 2009; Duggan \& Brenner, 2013). One study controlled for personality characteristics that may be related to social application usage (e.g., extraversion, emotional stability and openness to experience), and found similarly that young adults (18-29 years old) who grew up with digital options used social media tools as “digital natives” (Prensky, 2001), while those in the older cohort were more likely to engage with social media only if they are generally more open to new activities (Correa, Hinsley \& de Zúñiga, 2010). In addition, women are more likely to engage with social media than men, while education and race/ethnicity were not significant predictors of social media usage (Chou et al., 2009; Correa et al., 2010). The Pew Research Center conducted a comprehensive survey to examine demographic differences among different platforms in 2013. They found that Facebook mostly attracts women and young adults; Twitter specifically attracts a larger percentage of African-Americans and urban users; while Pinterest appeals to women and the white population with some college education experience. On the other hand, Instagram appears to attract more minorities within urban areas, such as African-Americans and Latinos (Duggan \& Brenner, 2013). The graph below summarizes some of the findings from the Pew Research Center's survey.

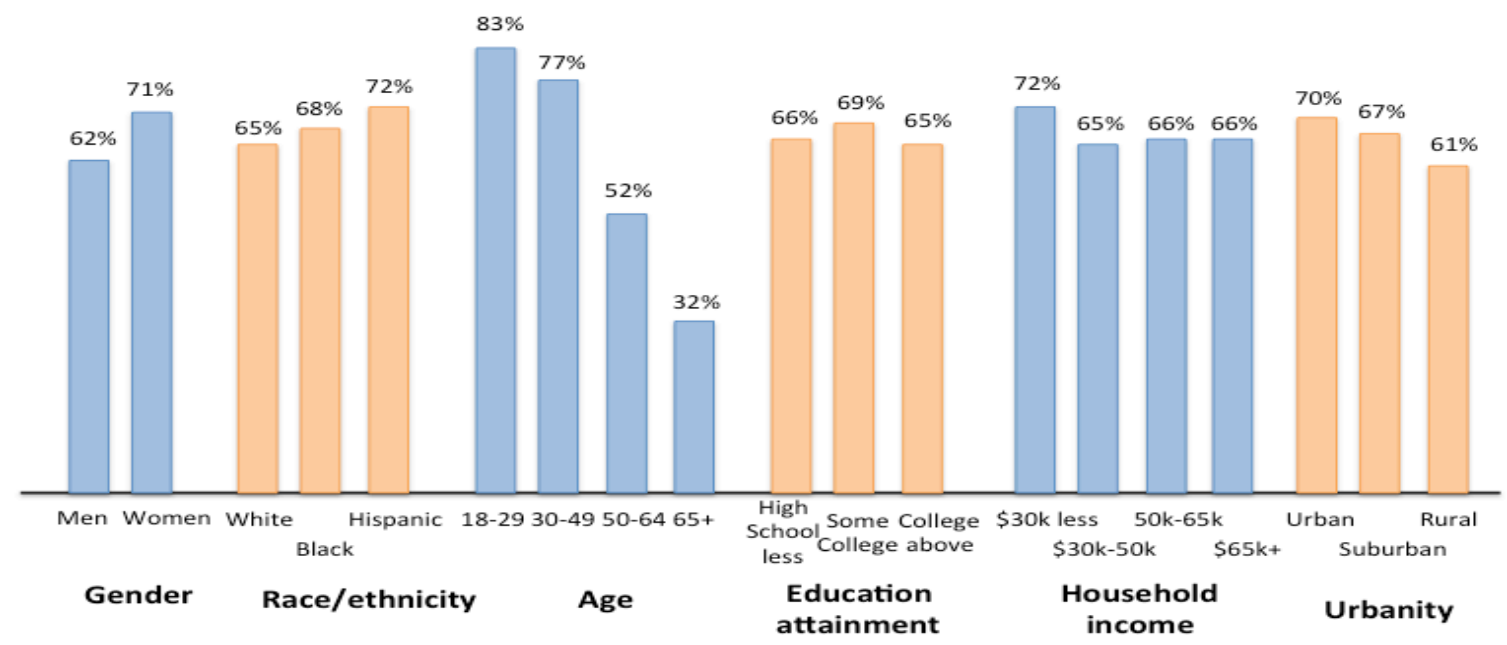

Figure 2. Percentage of Internet Users Who Use Social Networking Sites Source: Duggan \& Brenner (2013) 


\subsection{USE OF SOCIAL MEDIA PROGRAMS AND PERFORMANCE METRICS IN THE TRANSPORTATION INDUSTRY}

\subsubsection{Current Use and Goals of Social Media Programs}

Public transportation agencies are increasing their use of social media. In 2011, 54\% of public transportation agencies used Facebook, 51\% used Twitter and 37\% used YouTube, according to a survey led by The Urban Transportation Monitor ("The Use of Social Media by Transportation Agencies,” 2011). Bregman (2012) researched best practices for transportation agency use of social media and found that almost every state department of transportation, many public transit agencies and airports have a social media presence, representing a dramatic revolution in how governments interact with constituencies. Generally, agencies use the following social media platforms: social and professional networking, blogging, micro blogging, media and document sharing sites, social curation, geolocation and crowdsourcing (Bregman, 2012).

Social media is used by public transportation agencies to communicate brief messages, service updates, meeting notices, project updates, agency promotion, service tutorials, stories and testimonials. It is also used for community building and branding, networking, recruiting and indepth discussions. Reasons cited by agencies for using social media included provision of timely updates, communication of public information, citizen engagement, employee recognition and entertainment (Bregman, 2012). Social media has become part of the agencies’ marketing plans, but has also been used as a planning and emergency management tool. Agencies have used social media to accomplish the 4Es of social marketing: to entice their customers to participate, to exchange information with them, to engage them in social media dialogues, and to experience the interaction process leads to an overall impression (Raymond \& O’Hara, 2014).

The existing best practices as voiced by transit agencies include establishing the foundation for a social media program; finding the right persons to create, review and post messages; finding the right voice and language; using the right social media platform; developing the right content and

setting policies; committing to consistent communication; remembering that social media is not a unilateral communication medium and responding to criticism; using appropriate technologies that reach all audiences to ensure information equity; understanding that social media is only one communications tool and should be used in relation to others to ensure a comprehensive approach; and measuring the results (Bregman, 2012).

\subsubsection{The Benefits and Effectiveness of Using Social Media Programs}

Transportation agencies mainly utilize social media to establish direct lines of communication with customers, share stories, manage emergencies and address customers' concerns. Social media helps agencies widen their reach, and has allowed them to communicate with groups that are hard to engage with otherwise, such as youth. Furthermore, government transparency is enhanced with increased multilateral communication and access to public officials. 
Recent studies found that an interactive communicative style using social media could improve the overall image of an agency. Schweitzer (2014) analyzed transit rider sentiments towards public transportation agencies. Results showed that public transit received more negative sentiments than other agencies (parks departments and airlines), with a similar sentiment pattern of racist, ageist and other discriminatory comments as police departments and social welfare programs. However, the change in sentiments from 2010 to 2014 indicated that agencies that were "interactive" and responded directly to questions, concerns and comments of other social media users (instead of "blasting” announcements) received more positive statements and fewer slurs directed at patrons, independent of actual service quality, even if agencies responded only to a select number of tweets each day. One case example is the Southeastern Pennsylvania Transportation Authority (SEPTA), which consistently ranked at the bottom of negative Twitter comments in 2010 and improved its opinion score by 70\% only one year after it introduced its customer service dialog feed to run parallel with its blast feed (Schweitzer, 2014). However, customer service representatives do not have specific social media rules and regulations. SEPTA's tactic of embracing the online anger is to respond in a personable approach to all messages, display its own personalities and sign off with initials and emojis, creating a sort of relationship with the public (Marshall, 2015). Furthermore, attracting allies (planners, businesses, government agencies, enthusiasts, etc.) could also boost the overall sentiment expressed on social media (Schweitzer, 2014).

Another study found that creatively using crowdsourced information with social media can help to address the limitation of losing control of large amounts of outgoing information because of a staff shortage, thereby increasing the reliability of real-time information provision (Pender, Currie, Delbosc \& Shiwakoti, 2014). This strategy allows individuals both directly and indirectly affected to report a problem (rather than relying solely on media outlets). For example, the Pittsburgh bus system created a system called Tiramisu to increase interactivity between commuters and bus operators to accurately predict bus arrival time by crowdsourcing bus location and capacity information. In addition, an alert mechanism to inform commuters of potential disruptions to service was provided to address the reliability issue (Pender et al., 2014).

\subsubsection{Challenges and Practices of Using Social Media Programs}

There are several barriers to using social media that need to be considered when developing social media programs in transit agencies. The greatest barrier to adopting a social media program is staff availability. Social media represents significant investment of staff resources to maintain the sites, respond to users' comments and constantly update the public face of the agency. More than 50\% of large urban agencies surveyed in a 2011 study allocated a minimum of 40 hours per month to social media, while 23\% devoted more than 80 hours per month (Bregman, 2012). Meanwhile, social media may not be an effective way to save money, since the costs reduced from printed materials and postage may be offset by staffing costs. 
Another barrier is the difficulty of reaching certain group of people (i.e., those with disabilities, the elderly, etc.) and potential riders, although social media is a good way to communicate with current riders, especially young people. Other barriers are employee access between private and professional communications, responses to online critics, agencies' cyber security, archives and record retention, accessibility for all groups of people, user privacy, and transitioning from traditional communications tools to a social media landscape, according to Bregman's 2012 survey results.

Social media is still an emerging practice in transit agencies, which lack well-designed strategies and development goals. A survey of transportation providers across the country found that although $94 \%$ of those surveyed agencies used some form of social media, only $28 \%$ had a social media plan or strategy prior to implementation (Chin et al., 2012). In addition, there are still gaps between setting goals and effective ways to accomplish those goals, including improving customer satisfaction and the agency's image.

\subsubsection{Social Media Performance Metrics}

Given the wide usage and challenges of social media within public transportation agencies, the effectiveness of using social media is still unclear. Social media represents significant investments of staff resources to maintain sites, respond to users' comments and constantly update the public face of the agency on social media. Although social media replaces some communications via printed materials and physical mail, the savings from printing and postage may be offset by corresponding increases in social media staffing costs (Bregman, 2012).

Most agencies currently measure social media effectiveness through built-in metrics such as number of "friends and followers" or "likes," or by using third-party applications such as Google analytics. However, this information does not go far enough in justifying the investment of human resources for social media (Bregman, 2012). Simply collecting data without meaningful analysis is insufficient to understand the cost effectiveness of social media and return on investment. Metrics developed with specific business objectives and approaches in mind are more likely to be useful (Bregman, 2012; Owyang \& Lovett, 2012). Therefore, it is necessary for social media programs to tie in with the transportation agency's mission, purpose, operation objectives, priorities and communications plan. Social media program monitoring and measurement need to be institutionalized to ensure benefits are accounted for and the cost of the program is justified.

Some recent studies that develop social media performance metrics for public transit focus on "sentiment analysis" using Twitter for its real-time capabilities. Methods used included "text mining," scanning text for positive and negative opinion words, and “machine learning” how a computer selects information based on a programmed algorithm (Schweitzer, 2014). There are many advantages in using sentiment analysis to measure transit rider satisfaction (instead of transit surveys): minimal cost of data collection, data collected in real time, user-specific needs 
can be assessed, and the data can provide context to why a particular sentiment is felt. Sentiment analysis could provide customer feedback on fare increases, services and safety changes due to a lack of personnel (Collins, Hasan \& Ukkusuri, 2013). One program for sentiment analysis is SentiStrength, a machine-learning program that identifies the sentiment value of a short text by quantifying the general strength of the sentiment behind each text and average negative and positive sentiment. Total positive and negative sentiments are analyzed to identify if a time period had a significant increase or decrease. It can also analyze the specific time period to identify contributing factors to the change in sentiment (Collins et al., 2013).

\subsection{USE OF SOCIAL MEDIA PROGRAMS AND PERFORMANCE METRICS IN OTHER SECTORS}

Social media is also widely used in many industries other than transportation, among which healthcare and higher-education sectors have a longer usage history and advanced practical experiences. The social media usage from other industries would bring about transferable lessons to transportation agencies of strategies to construct social media structure, as well as performance metrics to measure effectiveness of usage.

\subsubsection{Current Usage and Purposes of Social Media}

Social media has been widely used in public and private organizations, which changes their communication tones in dialog. According to a survey of 15 top health systems in the United States, social media has transformed how healthcare providers communicate with the public, (Congeni \& Underwood, 2013). Sixty percent of state public health departments surveyed, as of 2012, use at least one social media application, with an average of one post per day (Thackeray, Neiger, Smith \& Van Wagenen, 2012). While in the higher-education sector, the Reform Support Network (2013) reported that state and local education agencies are fully leveraging the communication opportunities provided by social media and engaging stakeholders in critical conversations. Their survey shows that $80 \%$ of state education agencies (SEAs) and local educational agencies (LEAs) use or plan to use Twitter, Facebook, and YouTube, with a majority (79\%) reporting success with the use of social media. Out of all the agencies surveyed, 51\% indicated that they have policies to guide social media use. Two-thirds reported that they have a formal process for approving content of messages (Reform Support Network, 2013). However, use of social media by the public sector is still less than its use in the private sector. In one study, $44 \%$ of government agencies use social media but were still far from effective or strategic use (Havard Business Review, 2010). This was partially due to gaps in knowledge about what motivates citizens to interact with government. It seemed that citizens who were already engaged offline were also engaged online, but not vice versa (Smith, Schlozman, Verba \& Brady, 2009).

Social media is used as a channel for communication and engagement in public organizations. In healthcare, the purposes stated by agencies include communicating with consumers/patients; 
sharing information; improving clinical outcomes; speeding up innovations; managing reputation and brand; building customer relations; handling patient care and management; disseminating critical information; expanding reach to a broader audience; and fostering public engagement and partnership (CSC, 2012; Neiger, Thackeray, Burton, Giraud-Carrier \& Fagen, 2012). While in the private sector, social media is focused more toward advertising and branding purposes beyond communication. In one study, researchers interviewed six private-sector companies and found that the main purposes of using social media included branding, advertising and promotion; information sharing and searches; conducting market research; reaching new customers; getting referrals; developing customer relations; communicating with customers; customer service activities; and getting feedback from customers (Parveen, Jaafar \& Ainin, 2015). Reasons cited for government use of social media in a survey led by NASCIO (2010) included a desire to engage citizens, deepening outreach, disseminating information, and raising awareness. On the other hand, Smith (2010) reported that $74 \%$ of those surveyed viewed government agencies that use social media favorably and perceived them as more accessible.

Organizations indicate benefits of using social media, and claim social media enhances their performance. According to a study of six companies in different sectors, social media helps them enhance customer relationships and customer service; reduces marketing and customer service costs; improves information sharing and accessibilitys improves brand visibility; and even generates revenue and competitive advantages (Parveen et al., 2015).

However, there are challenges during social media usage and development in organizations. According to a survey of education agencies, staffing and human resources are the most severe obstacles (Reform Support Network, 2013). Agencies stated that an effective social media program is time consuming, with $91 \%$ indicating that they have dedicated staff who spend a quarter of their time working on social media tasks. Other concerns and barriers include negative postings by the public and critics; lack of training and resources; lack of staff expertise; privacy concerns; lack of commitment by decision makers; legal concerns; and clarity over who is responsible.

\subsubsection{Performance Metrics of Measuring Social Media}

Although positive anecdotal evidence abounds from social media usage in organizations that have taken the leap, little formal evidence is available to demonstrate the effectiveness and return on investment of social media use. This detracts some organizations from moving ahead with a social media strategy (CSC, 2012).

The most common measure to evaluate social media programs is by collecting platforms' subscriber or other tracking numbers that are easy to collect. In the healthcare field, MHA Degree studied hospitals' use of social media, and ranked and evaluated the top 50 "social media friendly hospitals” by their use of Facebook, Twitter, You Tube, LinkedIn, Google Plus, Pinterest and Flicker. The metrics they used for evaluating social media outcomes for each 
hospital were quantity of followers, likes, tweets, views, subscribers, group members, photos, and people talking about the hospital.

However, Congeni and Underwood (2013) indicated that those with the largest social media audience were not necessarily the most successful with social media. They pointed out that “engagement is the key to social media success.” Fyfe \& Crookall (2010) also recommended that to achieve effective use of social media, government agencies should analyze the costs, benefits and risks; find leaders who serve as champions; and carefully balance planning with spontaneity. They urged the creation of policy frameworks as well as allowing room for mistakes to happen and assess return on investment. However, the assessment of the return on investment poses difficulty when existing measurements are "rudimentary at best and need to be extended to gain more meaningful insights” (Mergel, 2012).

Therefore, more studies are emerging to develop more well-structured measurements and correspondent metrics. Studies indicate that effective use of social media programs within public health departments would develop a strategic communication plan that incorporates best practices for expanding reach, interactivity and audience engagement (Thackeray et al., 2012). Neiger et al. (2012) developed four key performance indicators (KPIs) and metrics to evaluate social media influence on health promotion based on the goals and purposes the organizations want to achieve. The four KPIs were reach, exposure, insights, and engagement. Reach measures the number of people who have contact with social media. Exposure measures impressions or the number of times the content on social media has been viewed. Insights are defined as consumer feedback from social media, including sentiment analysis or data mining. Engagement measures the link from social media to real actions. They further developed metrics for engagement activities into low, medium and high engagement level (Neiger, Thackeray, Burton et al., 2012). In addition, they applied Twitter as an example to describe the metrics: Low engagement measures early stages of implementation, most likely followers, subscribers, etc.; medium engagement measures the presence of dialogic conversation, such as number of retweets and responses to questions; and high engagement measures the outcome with a culminating indicator that reflects actions. In addition, these metrics can be selected and combined according to different purposes and goals the organization wants to achieve.

In the education sector, a survey of SEAs and LEAs found half of the participating agencies indicated that they measure the success and impact of their social media programs (Reform Support Network, 2013). The metrics used were audience reach, and the level of engagement and mentions by other users. Half of the agencies use an equal mix of quantitative and qualitative metrics for measuring the success of their social media program. The agencies gather quantitative data through analytics offered by specific social media platforms and growth of followers. Qualitative data is gathered to measure quality of interactions through stakeholder feedback and surveys. There is also evidence that agencies surveyed perceive social media as a multilateral communication tool that involves sending, receiving and responding to consumer inquiries and feedback. 
In practice, there are studies that applied sophisticated data mining approaches and sentiment analysis to learn and evaluate the use of social media. One study analyzes 3,000 tweets in 210 local health departments to examine how they use Twitter to share information, engage followers and promote actions through their tweets (Neiger et al., 2013). However, they found most tweets are one-way communication on personal-health topics and organization-related information, which indicates a mismatch of social media content and consumers' preferences. Therefore, it is necessary to create new and engaging content in future social media development. One way found to achieve this is to invite advocates and influencers to online conversations. Besides traditional access to systems such as Facebook Insights, Edge Rank and Google Analytics to objectively assess engagement on social media, it is critical to dedicate time and resources to social media programs in order to reap their benefits.

\subsubsection{Supplementary Lessons from Other Sectors}

Effective use of social media would require a cultural shift from the old ways of government. Interactions with the public would have to move from a bureaucratic approach, where anonymous public officials resort to a centralized, one-way form of communication, to decentralized, two-way communications where government agencies do not just talk to but listens to people as well. The feedback would be used to inform services and decisions (Fyfe \& Crookall, 2010). Government employees also need to change their perspective about social media from the view of these tools as technology tools to the view that they are communication tools (Godwin, Campbell, Levy \& Bounds, 2008). Fyfe \& Crookall (2010) argued for greater engagement with the public in an open manner that emphasizes building relationships. Galloway \& Guthrie (2010) recommended that online relationships be built on frequent contacts, interesting content and feedback. Wigand (2012) argued that relationships were shaped by chosen social media channels, the content of messages, reciprocity, volume, direction, and frequency of communication. There is a need to understand the online behavior of users and their motivation to be able to effectively engage them.

In addition, Bretschneider \& Mergel (2010) underscore the need to connect an organization's social media use to its mission and goals. The Open Government Directive of 2009 provided four benchmarks; transparency, accountability, participation and collaboration. Performance metrics for social media can measure the extent to which it enables agencies to accomplish these benchmarks.

The social media experience in healthcare organizations suggests that effective use should accomplish the following strategies: Set goals for a social media program that are consistent with marketing goals; determine metrics that track outcomes and ensure movement in the right direction; and create social media guidelines for employees to create a consistent and professional image (Congeni \& Underwood, 2013). 
Some of the major concerns of public agencies related to social media policy revolve around legal, security and privacy issues. According to The League of California Cities'Institute for Local Government's Ethics Project (2010), there are multiple legal issues that a government agency should consider when designing a social media program, including:

- First Amendment issues relating to government restrictions on speech;

- Use of public resources, including both personal and political use;

- Restrictions on employee use of social media, both on behalf of the agency and personally;

- Open meetings law issues; and

- Public records retention and disclosure issues.

Furthermore, Center for Technology in Government (CTG) identified eight elements of social media policy that need to be addressed: employee access, account management, acceptable use, employee conduct, content, security, legal issues and citizen conduct. Due to the blurring lines of personal and professional use, agencies managed employee access by limiting the number or types of employees allowed access as well as the signing of an official business case justification. Strategies for account management included assigning only one party to approve and manage accounts, usually the Information Officer or the communications and IT department. Acceptable use policies provided employees limits on personal use and consequences for violations, which were normally an extension of existing policies for telephone and computer access. Employee conduct usually addressed use of offensive language and consistency with agency values, which CTG recommended should be extended to social media programs. There were also behavioral security concerns from employees' intentional or inadvertent actions, such as what was discussed in the Guidelines for Secure Use of Social Media by Federal Departments and Agencies by the Federal CIO Council (Hrdinova, Helbig \& Peters, 2010). 


\subsection{HOW AGENCIES USE SOCIAL MEDIA - SURVEY RESULTS}

We conducted surveys of transit agencies to understand the usage of social media in terms of program structure, human resources investment, purposes of use, and performance metrics. In addition, two other surveys were administered to healthcare and higher-education organizations, which are sectors where social media programs have been applied for longer periods than public transportation. These two sectors both tend to provide public services for common users, similar to transit agencies. Their social media usage experiences and development directions may provide some direction for how advancements may be made in the public transit agency social media usage. Similar questions were asked in the transit agencies' survey as those in the surveys administered to the healthcare and higher-education organizations. The similarities and differences of the three survey results are compared, and policy suggestions from the three surveys are summarized at the end of this section.

\subsection{TRANSIT AGENCIES' SURVEY}

The research team conducted an online survey of top transit agencies around the country in early 2015. In this survey, we collected general information about the agency's usage of social media programs, what purpose they use social media for and how they measure their programs. For example, how their social media programs are structured (e.g., goals, objectives, measurements, strategies, etc.); which platforms they use; how many staff members are involved in social media responsibilities; at what frequencies they use social media for various purposes; how they measure their social media program outcomes; and how they value these usages and metrics. The survey questions are included in Appendix A.

To construct the survey panel of transit agencies, we started with the Transit Profiles: Top 50 Agencies report from Federal Transit Administration's (FTA) National Transit Database (NTD). Additional contact information regarding individual staff members in each agency who manage the social media program was found through online searches and verified via email and phone. The survey commenced in January 2015 with 43 public transportation agencies on the survey panel, and three rounds of reminders via emails and phone calls were sent to agencies that did not complete the survey to generate as many responses as possible. 


\subsection{TRANSIT AGENCIES' RESPONSES}

\subsubsection{Responding Agencies}

The survey was sent to a panel of 43 public transit agencies around the U.S. Twenty-seven agencies completed the survey, representing a $63 \%$ response rate.

Due to human subject confidentiality restrictions regulated by an institutional review board, we cannot fully list the name of responding agencies. Therefore, we categorized the average characteristics of the responding agencies by region in Table 1 with additional demographic data from the Census and transit operations and supply data from FTA's NTD. We have a diverse mix of responding agencies representing larger metropolitan areas as well as mid-sized cities in terms of geographical area and population size. They represent an average percentage of population within the 18-44 age group (between $36.9 \%$ and $39.4 \%$ ); between $11.1 \%$ and $13.2 \%$ population aged 65 and above; and between 28.6\% and 37.5\% of the population who identify as non-white. These agencies operate approximately 773 to 1,262 vehicles at maximum, with an average of 18 million to 25 million vehicle revenue miles, servicing 40 million to 80 million unlinked passenger trips on average annually.

Table 1. City and Agency Attributes of Responding Public Transit Agencies

\begin{tabular}{lcccc}
\hline & Midwest & Northeast & South & West \\
\hline Agencies Sampled & 6 & 10 & 11 & 16 \\
Number of Responses & 4 & 7 & 5 & 11 \\
\hline Demographics (average) & & & & \\
$\quad$ Service area (sqkm) & 5,254 & 2,916 & 2,464 & 2,008 \\
Service population & $3,922,902$ & $2,059,246$ & $1,800,018$ & $1,896,442$ \\
\% age 18-44 & $37.3 \%$ & $36.9 \%$ & $39.4 \%$ & $39.0 \%$ \\
\% age 65+ & $11.5 \%$ & $13.2 \%$ & $11.1 \%$ & $11.6 \%$ \\
$\quad$ \% non-white & $28.6 \%$ & $32.8 \%$ & $31.3 \%$ & $37.5 \%$ \\
\hline Transit Operations (average) & & & \\
$\quad$ Vehicles operated in & 975 & 1,262 & 773 & \\
$\quad$ annual maximum service & $25,122,218$ & $18,871,957$ & $18,748,511$ & $18,375,619$ \\
$\quad$ Vehicle revenue miles & $3,357,675$ & $2,872,843$ & $2,830,736$ & $2,564,176$ \\
$\quad$ Deadhead miles & $54,217,603$ & $80,347,369$ & $40,335,393$ & $53,452,994$ \\
$\quad$ Unlinked passenger trips & & & & \\
\hline
\end{tabular}

\subsubsection{Socials Media Usage and Measurement in Public Transit Agencies}

All responding public transit agencies (including incomplete responses from two agencies) indicate some level of social media presence. The structure of their social media programs usually includes some planning and/or evaluative processes, with $79 \%$ structured with social media strategies; $76 \%$ with methods to measure results and targeted audiences; and $62 \%$ with clearly defined goals and measurable objectives. Nearly all agencies use multiple social media platforms, averaging 3.7 platforms. Twitter, Facebook and YouTube are the most commonly used social media, with $100 \%$, 93\% and $83 \%$ of the agencies using each of these three platforms, 
respectively. In addition, nearly half of the respondents also use Instagram, while a handful of agencies indicate usage of LinkedIn, Flickr, Pinterest and SmugMug, etc.

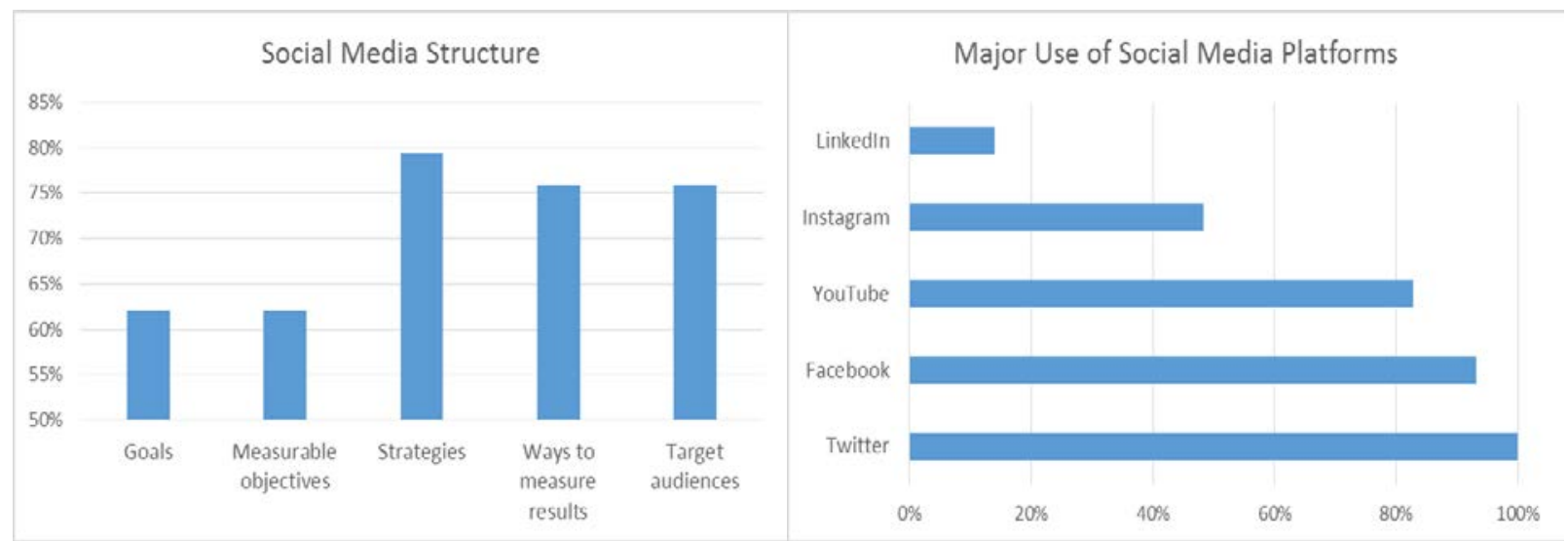

Figure 3. Social Media Structure and Major Platforms Among Transit Agencies

In terms of staff resources invested in social media, most agencies (including incomplete responses from two agencies) have multiple staff members working on their social media programs. Over $40 \%$ of responding public transportation agencies have full-time staff exclusively dedicated to social media work, with an average of 1.33 full-time equivalent staff members. In many agencies (59\%), while there are not personnel dedicated exclusively to social media communications, the responsibility is spread amongst multiple staff members who have other job responsibilities, averaging around five employees. A small proportion of agencies (10\%) have one person fully dedicated to social media, but no other staff have any social media responsibilities. Meanwhile, many agencies have some kind of guidelines and training for staff with social media responsibilities. However, different agencies are at different stages. Some have comprehensive policies, strategies and guidelines, while others are still in the process of developing policies and strategies.

Public transit agencies responded to questions regarding the frequency that they used social media communication for specific purposes and how much they valued these uses. We found that public transit agencies most frequently use social media to respond to comments from their customers and communicate available services, as shown in Figure 4. More than half of the agencies frequently use social media to provide transit system information and updates, but less than a quarter of the agencies frequently use social media as a channel to provide transit-related livability or sustainability benefits, such as how public transit enhances quality of life, reduces congestion, enhances positive environmental impacts and addresses safety issues. Although social media is not frequently utilized to provide messages and information regarding livability or sustainability enhancements through public transportation, we found public agencies place a relatively high value on this type of livability-related usage of social media, compared to other usages. 
As the agencies dictated, social media programs help them to achieve multiple goals besides communication. The social media program integrates into agencies' customer service, marketing and overall outreach. Communication through those platforms contributes to customers' positive experience and perception of reliability based on timely information updates and feedback, therefore increasing ridership in general. Social media programs also serve as a marketing toolkit for branding and promotion, even for recruitment. In addition, it helps transit agencies to increase openness and transparency.

With regards to the measurement of social media usage, we found more than half of public transit agencies frequently measure their social media programs through users' engagement activities and subscriber levels. Few of them are likely to measure their social media outcomes utilizing users' positive perceptions similar to sentiment analysis, such as the number of people who are receiving real-time information; number of people who consider public transit agencies as reliable and/or environmentally sensitive; and number of positive-toned messages about the transit agencies. For all types of measurement of social media outcomes, we observe public transit agencies place higher average values than average frequencies, underscoring the underlying need to not only utilize social media but to better understand its impacts and outcomes. Additionally, we observe a similar trend when we analyze the purposes of social media usage: The discrepancies between the frequency of use of measurement metrics and the perceived value of these metrics by public transit agencies are much greater for those metrics that are less frequently utilized.

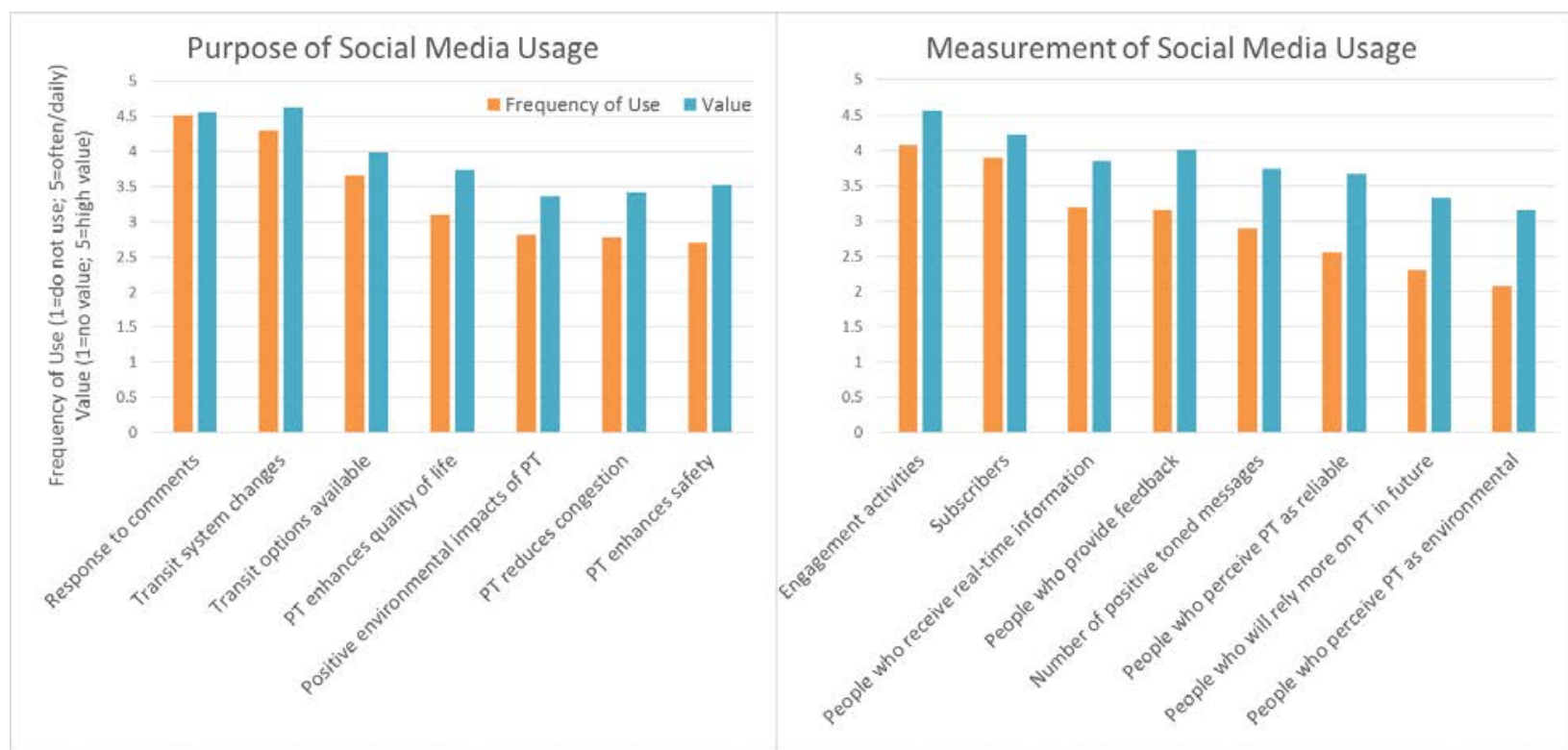

Figure 4. Purpose and Measurement of Social Media Usage in Transit Agencies

In addition, agencies call for more comprehensive metrics to measure their social media performance. Besides simply counting subscribers and engagement activities, which they most frequently use, they desire multiple tracking mechanisms to holistically capture web traffic and 
get greater insight into the quality of messaging. Return on investment (ROI) in social media is another concern for them. Some agencies want cost-effective performance tools to evaluate social media, specifically for governmental agencies.

\subsubsection{Social Media Usage Across Regions and Agencies}

Social media programs and usage patterns also vary across geographic regions, as shown in Table 2. Public transit agencies in the Northeast tend to have more staff members (either full time or other staff) working on social media programs on average, while agencies in the West are more likely to structure their social media staffing to spread responsibilities amongst multiple staff members instead of dedicated social media employees. On average, agencies in the Midwest have social media programs with the most structured components (e.g., goals, objectives, strategies, ways to measure results and target audiences), and engage in an average of 4.25 social media platforms, even though these agencies did not have the largest number of exclusive social media employees or other staff members.

In terms of the purpose of using social media, agencies in the West use social media less frequently to provide transit system information or to convey transit-related benefits to the public compared to their counterparts across the country. Agencies in the West typically utilize social media most frequently for responding to users' comments and criticisms. In contrast, agencies in the South spread their social media usage across diverse purposes. Similarly, agencies in the West value responding to users through social media much more compared to agencies in other regions, and more importance is placed on this particular use when compared with other purposes of social media.

When asked about the measurement of their social media program through various metrics, all Midwest responding agencies indicated the usage of some social media measurement metric, while only $80 \%, 73 \%$ and $71 \%$ of agencies in the South, West and Northeast regions employed metrics, respectively. Agencies in the South and the Midwest are more likely to use multiple metrics to measure their programs than the other two regions. Numerous comments from agencies specifically point out the lack of uniform performance measures and best practices available for social media usage.

Expanding upon the descriptive statistical analysis, we conducted a correlation analysis with results presented in Figure 5. The colored dots in this correlation matrix represent correlation relationships between public transit agency social media usage characteristics that we obtained from our survey results and city/agency demographic and transit operation attributes that are statistically significant at 5\%, with red dots indicating positive correlation and blue dots indicating negative correlation. Although one would surmise that larger cities may utilize social media at a higher rate due to a larger geographic area, diverse population, the public transit agency's need to communicate with a large audience and more resource availability, we find that 
this is not the case according to our survey results. Larger cities, measured in terms of public transit service area and population size, show weak correlations with almost all measures of social media usage in general. In addition, agencies in larger cities appear more likely to use social media to provide transit system information as opposed to communicating livability benefits of public transit or interacting directly with users. However, larger transit systems, in terms of the maximum number of operating vehicles, vehicle revenue miles (VRM) and unlinked passenger trips, are positively associated with more labor inputs invested in social media programs.

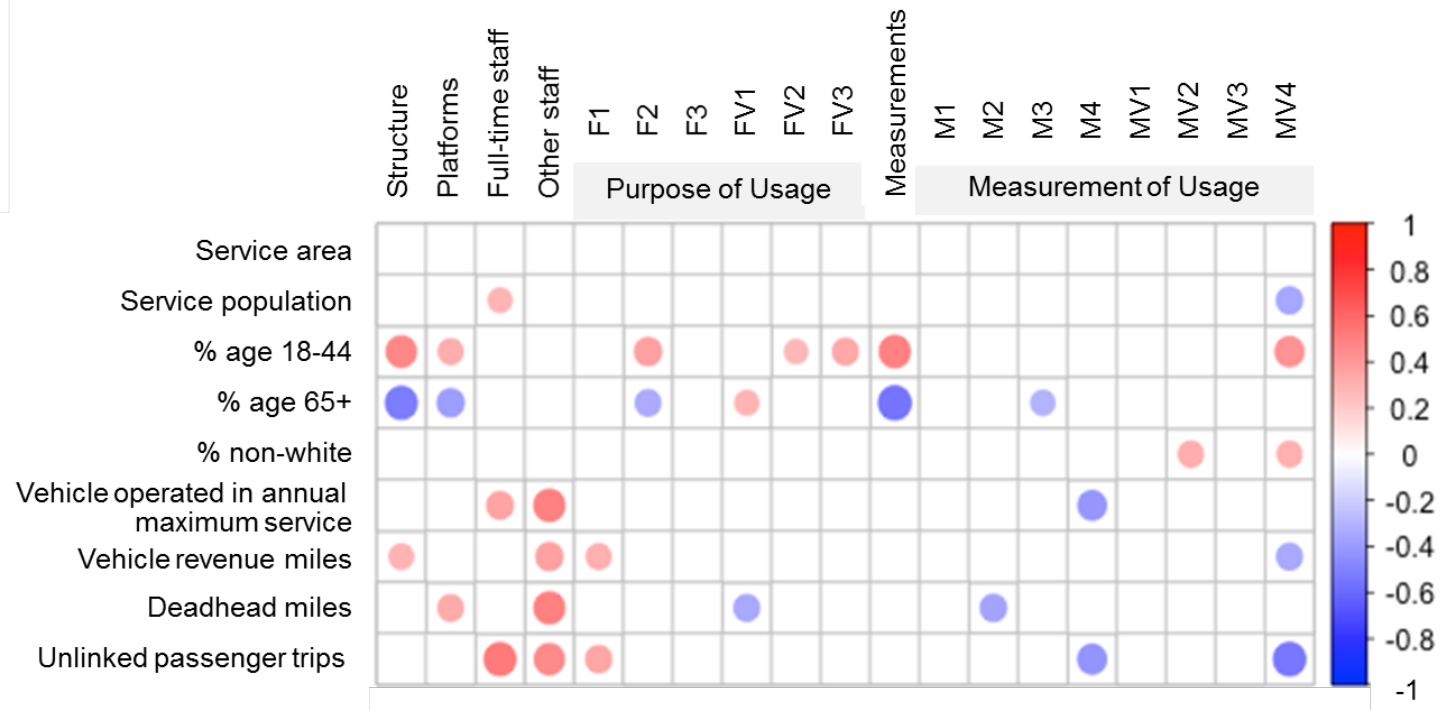

Figure 5. Correlation Matrix of Social Media Usage and City/Agency Attributes (n=27) Note: Please refer to Table 2 for variable descriptions.

On the other hand, the age composition within a city is strongly correlated with agencies' social media usage, in terms of social media program structure, purpose of use and performance metrics. This result fits with intuition and previous research that indicate a stronger engagement of the younger population through social media platforms, although this may be a shifting trend. If the proportion of people in the 18-44 age group is higher in a city, the public transit agency's social media program is more likely to be structured with multiple components, engaged in a greater number of social media platforms, and would be used for a larger variety of purposes. In addition, “younger cities” are positively associated with the usage of multifaceted social media metrics, and tend to place particular importance on whether or not social media users are indicating a commitment to utilize public transportation more in the future. These strong correlation patterns are reversed when considering the percentage of population aged 65 or above. Racial composition generally has no relationship with social media usage, which implies 
that the usage and measurement of social media appears to be consistent regardless of the level of racial diversity within the service population.

Table 2. Social Media Usage Survey Results by Region

\begin{tabular}{|c|c|c|c|c|c|}
\hline Variable & Midwest & Northeast & South & West & $\begin{array}{l}\text { Overall } \\
\text { Average }\end{array}$ \\
\hline Social media program structure ${ }^{1}$ & 4.00 & 3.43 & 3.80 & 3.45 & 3.59 \\
\hline Number of social media platforms & 4.25 & 3.14 & 3.60 & 3.91 & 3.70 \\
\hline Full-time staff dedicated to social media & 0.75 & 0.93 & 0.60 & 0.30 & 0.58 \\
\hline Other staff with social media responsibilities & 3.25 & 4.86 & 2.60 & 6.93 & 5.04 \\
\hline \multicolumn{6}{|l|}{ Purpose of Social Media Usage } \\
\hline \multicolumn{6}{|l|}{ Frequency of Use ${ }^{2}$} \\
\hline For transit information updates $[\mathrm{F} 1]$ & 4.25 & 4.29 & 4.20 & 3.64 & 4.00 \\
\hline For conveying transit related livability benefits & 2.88 & 2.68 & 3.35 & 2.73 & 2.85 \\
\hline For communication with users [F3] & 4.50 & 4.29 & 4.80 & 4.55 & 4.52 \\
\hline \multicolumn{6}{|l|}{ Value of Use } \\
\hline For transit information updates [FV1] & 4.13 & 4.57 & 4.40 & 3.41 & 4.31 \\
\hline $\begin{array}{l}\text { For conveying transit related livability benefits } \\
\text { [FV2] }\end{array}$ & 3.75 & 3.21 & 4.00 & 3.41 & 3.52 \\
\hline For communication with users [FV3] & 4.50 & 4.29 & 4.60 & 4.73 & 4.56 \\
\hline \multicolumn{6}{|l|}{ Measurement of Social Media Usage } \\
\hline Measurements ${ }^{4}$ & 1.00 & 0.71 & 0.80 & 0.73 & 0.78 \\
\hline \multicolumn{6}{|l|}{ Frequency of Use $e^{5}$} \\
\hline Number of subscribers [M1] & 4.25 & 4.43 & 4.60 & 3.18 & 3.89 \\
\hline Users' positive perception/sentiments [M2] & 3.13 & 3.12 & 2.70 & 2.27 & 2.70 \\
\hline Users' engagement [M3] & 4.25 & 3.86 & 4.00 & 3.18 & 3.61 \\
\hline $\begin{array}{l}\text { Future commitment to utilize public transit } \\
\text { [M4] }\end{array}$ & 2.50 & 2.14 & 3.00 & 2.27 & 2.30 \\
\hline \multicolumn{6}{|l|}{ Value of $U s e^{6}$} \\
\hline Number of subscribers [MV1] & 4.00 & 4.71 & 4.60 & 3.82 & 4.22 \\
\hline Users’ positive perception/sentiments [MV2] & 3.75 & 3.61 & 3.70 & 3.50 & 3.60 \\
\hline Users' engagement [MV3] & 4.63 & 4.36 & 4.30 & 4.09 & 4.28 \\
\hline $\begin{array}{l}\text { Future commitment to utilize public transit } \\
\text { [MV4] }\end{array}$ & 3.00 & 3.00 & 3.80 & 3.45 & 3.33 \\
\hline
\end{tabular}

Notes:

1. Structure: How is the social media program structured? This value varies from 0 to 5 , indicating the total number of social media program components (goals, objectives, strategies, ways to measure results and target audiences) that exist in the public transit agency.

2. Purpose of Social Media Usage - Frequency of use: How frequently the public transit agency uses social media for specific purposes? Frequency ranges from 1 to 5, indicating do not use, infrequent, somewhat, frequent and often/daily.

3. Purpose of Social Media Usage - Value of use: How valuable is the usage of social media for specific purposes at the public transit agency. Value of use ranges from 1 to 5 to represent no value, little, some, valued, and high value.

4. Measurements: Whether the agency’s social media program is structured with ways to measure results $(1=$ yes; $0=$ no $)$

5. Measurement of Social Media Usage - Frequency of use: How frequently the public transit agency measures its social media usage using certain metrics. This value ranges from 1 to 5 , stands for no use, somewhat, frequent and often. 
Frequency ranges from 1 to 5, indicating do not use, infrequent, somewhat, frequent and often/daily.

6. Measurement of Social Media Usage - Value of use: How valuable of the agency measure social media using certain metrics. Value of use ranges from 1 to 5 to represent no value, little, some, valued, and high value.

\subsubsection{Factors Influencing Social Media Usage in Public Transit Agencies}

To delve further into understanding factors that determine public transit agencies' social media usage, we constructed several multivariate regression models. These models are not intended to determine causality of certain attributes on social media usage or participation by agencies; rather, these types of regression specifications allow us to expand upon one-on-one correlation analysis to allow us to elucidate how specific attributes of agencies or cities are related to social media usage and measurement while controlling for other variables. The regression models results with the best goodness-of-fit measures are shown below in Table 3, and standardized coefficients are reported to reflect the independent variables, which have the largest effects in describing the usage of social media. We find that social media usage is most significantly determined by agencies’ geographic region, age composition of the city, and public transportation system characteristics.

In our regression analysis, we use a variety of variables as proxies for the extent of social media usage as the dependent variable. In Model 1, an agency's social media program structure, as well as whether it includes components such as goals, objectives, strategies, ways to measure results and target audiences, is the dependent variable. The number of full-time staff members with exclusive social media responsibilities is modeled in Model 2 to explore the determinants of resource investment. Models 3 to 5 utilize dependent variables, which represent how public transit agencies measure social media usage or outcomes. R-squared values range between 0.30 and 0.478 for the estimated models, indicating that the explanatory variables describe approximately $30 \%$ to $47.8 \%$ of the variation in various measures of social media usage. Fstatistics for all models indicate statistical significance at $5 \%$ or better.

In Model 1 and Model 2, unlinked passenger trips (UPT) is the most positive predictor of both social media structure and number of full-time social media staff, which means the transit service consumption is the most important determinant of social media program structure and labor investments. The number of vehicles operated in annual maximum service (VOMS) and vehicle revenue miles (VRM) is estimated to have negative and significant coefficients in these models. It is interesting to note that transit service consumption or usage (UPT) and the service supplied (VOMS and VRM) have opposite effects on social media usage. Controlling for other variables, the agencies with more passenger trips and that provide a lower supply of transit services, or efficiently serve a larger number of trips with fewer vehicles or miles, strongly indicate a more comprehensive social media program structure and higher levels of labor inputs in their 
programs. These two models confirm that while population size and having a younger population positively influence social media usage (although not statistically significant), the percentage of senior population shows statistically significant negative impacts on the structure of social media programs. It fits with common intuition that older people in the cities are less likely to be active in social media.

In Model 3-1, we confirm the descriptive analysis detailed above that agencies in cities with a younger population tend to have a significantly higher likelihood of using some type of social media metrics. With a population and generation that are engaged with social media on a daily (or even hourly) basis, it is reasonable these agencies are invested in figuring out how well their social media program is reaching its audiences and whether engagement and interaction on social media may meet the agency's objectives and goals. Again, regional differences in the measurement of social media usage and outcomes are evident in these models. Similar to Models 1 and 2, we find that agencies with higher-service consumption and lower-service provision to be more engaged in the measurement of their social media at present. Agencies typically aim to reduce deadhead miles in order to increase operational efficiency. Interestingly, the regression model (3-2) shows that the higher the transit service operation efficiency, in terms of fewer deadhead miles, the lower the likelihood of using social media metrics. This is possibly an indication of the allocation of resources towards managing transit operations rather than towards communications or outreach in these types of agencies.

Model 4 and Model 5 are constructed to more thoroughly examine the factors that influence the specific kind of measurement metrics used by agencies. Agencies in the West less frequently use metrics that measure users' positive perception of public transit services or users' level of engagement with transit agencies, which possibly is due to their lower social media staff levels and social media programs with fewer structural components (Table 2). Again, age composition in the public transit agency's city significantly affects the usage of social media metrics. Agencies in cities with a younger population use positive perceptions and engagement measures more frequently as social media metrics.

In conclusion, we find that public transit service consumption or usage and the level of transit service provision are the most significant determinants of public transportation agencies' social media programming and labor resource investments. In contrast, the measurements of social media usage and outcomes are determined more by city attributes and demographic characteristics, such as age composition and geographic region. 
Table 3. Regression Model Results with Standardized Coefficients (t-statistic) for Social Media Usage $(n=27)$

\begin{tabular}{|c|c|c|c|c|c|c|}
\hline Variables & $\begin{array}{c}\text { Model 1 } \\
\begin{array}{c}\text { Social Media } \\
\text { Structure }\end{array}\end{array}$ & $\frac{\text { Model } 2}{\begin{array}{c}\text { Full-time } \\
\text { Staff }\end{array}}$ & \multicolumn{2}{|c|}{$\begin{array}{l}\text { Use of Social Media } \\
\text { Measurement Metrics }\end{array}$} & $\begin{array}{c}\text { Model } 4 \\
\begin{array}{c}\text { Positive } \\
\text { Perception }\end{array}\end{array}$ & $\begin{array}{c}\text { Model 5 } \\
\text { Engagement }\end{array}$ \\
\hline \multicolumn{7}{|c|}{ Geographic variables (reference region = Midwest) } \\
\hline Region - Northeast & & & $\begin{array}{l}-0.207 \\
(-0.85)\end{array}$ & $\begin{array}{l}-0.075 \\
(-0.33)\end{array}$ & $\begin{array}{l}0.049 \\
(0.22)\end{array}$ & $\begin{array}{l}-0.034 \\
(-0.14)\end{array}$ \\
\hline Region - South & & & $\begin{array}{l}-0.464 * \\
(-1.85)\end{array}$ & $\begin{array}{l}-0.449 * \\
(-2.04)\end{array}$ & $\begin{array}{l}-0.336 \\
(-1.46)\end{array}$ & $\begin{array}{l}-0.131 \\
(-0.60)\end{array}$ \\
\hline Region - West & & & $\begin{array}{l}-0.581^{*} \\
(-2.06)\end{array}$ & $\begin{array}{l}-0.471^{*} \\
(-1.86)\end{array}$ & $\begin{array}{c}-0.627 * * \\
(-2.51)\end{array}$ & $\begin{array}{c}-0.584^{* *} \\
(-2.44)\end{array}$ \\
\hline Service area (sqkm) & & & $\begin{array}{l}0.092 \\
(0.51) \\
\end{array}$ & $\begin{array}{l}0.289 \\
(1.58)\end{array}$ & & \\
\hline \multicolumn{7}{|l|}{ Demographic variables } \\
\hline Service population & & $\begin{array}{l}0.268 \\
(1.61)\end{array}$ & & & & \\
\hline$\%$ age $18-44$ & & $\begin{array}{l}0.193 \\
(1.19)\end{array}$ & $\begin{array}{c}0.715^{* *} \\
(3.64)\end{array}$ & $\begin{array}{c}0.909 * * * \\
(4.89)\end{array}$ & $\begin{array}{l}0.394^{*} \\
(2.00)\end{array}$ & \\
\hline$\%$ age $65+$ & $\begin{array}{c}-0.707 * * * \\
(-4.66)\end{array}$ & & & & & $\begin{array}{c}-0.509 * * \\
(-2.74)\end{array}$ \\
\hline \multicolumn{7}{|c|}{ Transit operation variables } \\
\hline $\begin{array}{l}\text { Vehicles operated in } \\
\text { annual maximum } \\
\text { service }\end{array}$ & $\begin{array}{c}-0.545^{*} \\
(-2.63)\end{array}$ & & & $\begin{array}{c}-0.718^{* *} \\
(-2.74)\end{array}$ & & $\begin{array}{c}-0.415 * \\
(-1.76)\end{array}$ \\
\hline $\begin{array}{l}\text { Vehicle revenue } \\
\text { miles }\end{array}$ & & $\begin{array}{c}-0.516 * * \\
(-2.33)\end{array}$ & & & $\begin{array}{c}0.298 * \\
(1.74)\end{array}$ & \\
\hline Deadhead miles & & & & $\begin{array}{c}0.413^{* *} \\
(2.30)\end{array}$ & $\begin{array}{c}-0.403 * * \\
(-2.26)\end{array}$ & \\
\hline $\begin{array}{l}\text { Unlinked passenger } \\
\text { trips }\end{array}$ & $\begin{array}{l}0.806 * * * \\
(3.72)\end{array}$ & $\begin{array}{c}0.84 * * * \\
(3.84)\end{array}$ & & $\begin{array}{c}0.486^{* *} \\
(2.22)\end{array}$ & & $\begin{array}{c}0.517^{* * *} \\
(2.09)\end{array}$ \\
\hline Adjusted R-square & 0.478 & 0.354 & 0.300 & 0.466 & 0.357 & 0.328 \\
\hline $\begin{array}{l}\text { F-statistic } \\
\text { (p-value) }\end{array}$ & $\begin{array}{c}8.93 \\
(0.000)\end{array}$ & $\begin{array}{c}4.56 \\
(0.008)\end{array}$ & $\begin{array}{c}3.32 \\
(0.026)\end{array}$ & $\begin{array}{c}3.83 \\
(0.009)\end{array}$ & $\begin{array}{c}3.42 \\
(0.018)\end{array}$ & $\begin{array}{c}3.11 \\
(0.026)\end{array}$ \\
\hline
\end{tabular}




\subsection{HEALTHCARE ORGANIZATIONS' SURVEY RESPONSES}

We began with Social Media Health Network, a network that organizations and individuals want to apply social media in health care lead by Mayo Clinic, to build the healthcare survey panel. From there, we searched for contact information of the individual staff member in each organization who managed the social media through internet research. There are 83 contacts from 73 organizations in total, which are from 33 states in the U.S. and one from Australia. The survey was sent to the panel organizations, and seven completed responses from six organizations were received. We averaged the responses from the same organization as one. We also had one organization with an incomplete response.

All responding healthcare organizations (including incomplete responses from one organization) indicate some level of social media presence. The structure of their social media programs usually includes some planning and/or evaluative processes, with $71 \%$ structured with targeted audiences and strategies; 57\% with ways to measure social media results; and 36\% with clearly defined goals and measurable objectives. Nearly all agencies use multiple social media platforms, averaging 4.6 platforms. Similar as transit agencies, Twitter, YouTube and Facebook are the most commonly used social media, with $100 \%, 100 \%$ and $86 \%$ of the agencies using each of these three platforms, respectively. In addition, nearly half of the respondents also use Instagram and LinkedIn, while a handful of agencies indicate usage of Google+ and Pinterest, etc.

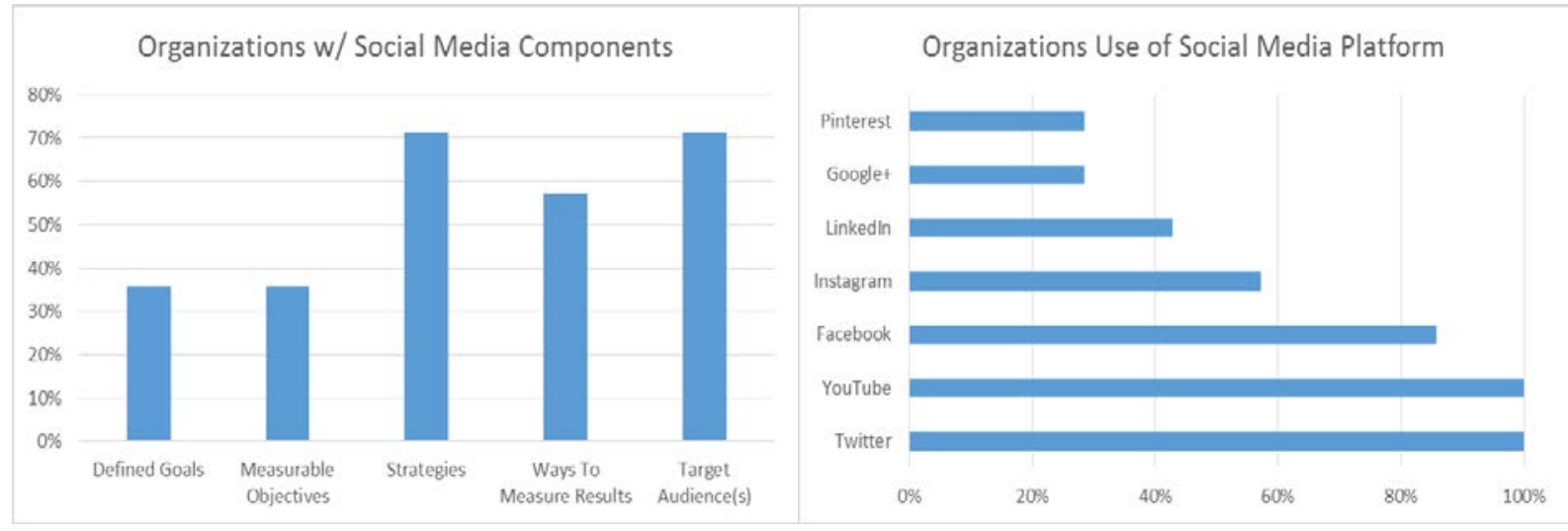

Figure 6. Social Media Program Components and Platforms

In terms of staff resources invested in social media, most organizations (including incomplete responses from one organization) have multiple staff members working on their social media programs. Over half of responding public transportation agencies have full-time staff exclusively dedicated to social media work. Almost all organizations have multiple staff share the responsibility of social media tasks, averaging around two employees. 
Healthcare organizations most frequently use social media to communicate available services and respond to comments from their customers, as shown in Figure 6. Some organizations utilize social media as a means of advertising and community engagement. However, they consider these marketing purposes are even more valuable than common communication purposes.

Similarly to transit agencies, healthcare organizations measure their social media programs through users' engagement activities and subscriber levels. Some of them are likely to measure their social media outcomes utilizing users' positive perceptions, such as general satisfaction, perception of receive real-time information and positive tone messages. Although they have not utilize these measures as much as engagement activities and subscriber levels, they consider these metrics are more important than they currently utilize, which indicates the necessity to further explore these measures for practical use. As some of the organizations indicated, they want to strengthen their online community, and define a social media measurement index to reflect the efficiency of all online activities.

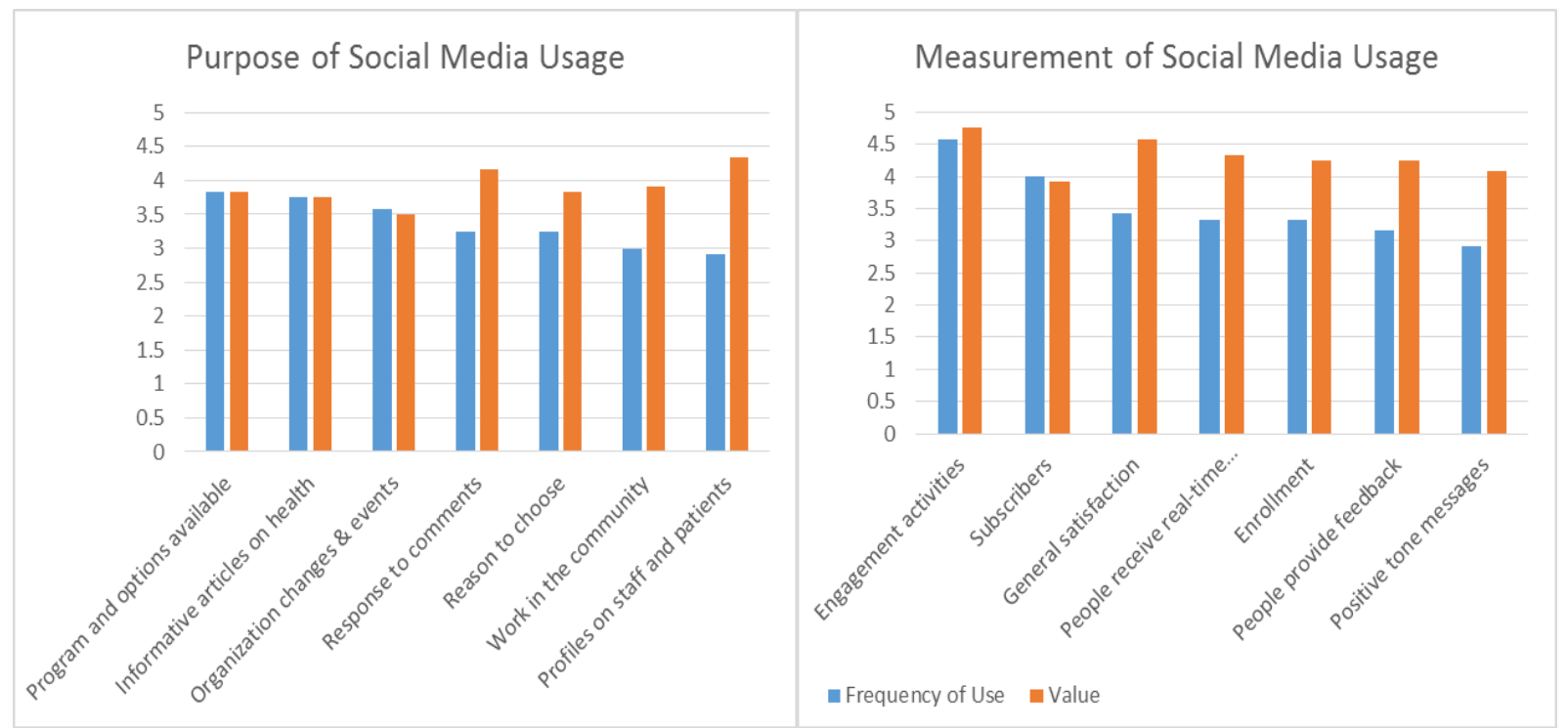

Figure 7. Purpose and Measurement of Social Media Usage in Healthcare Organizations

\subsection{HIGHER-EDUCATION ORGANIZATIONS' SURVEY RESPONSES}

We surveyed higher-education organizations in the states of New York and Oregon. The limited geographic scope of these surveys is a function of resource limitations, and the states chosen are the ones where the researchers are located and are most familiar with. The list of communication managers in higher-education organizations from New York was provided by the RPI team through previous connections. The PSU team put together a list for Oregon higher-education organizations from Wikipedia's “List of colleges and universities in Oregon.” From there, we searched for managers of social media from each organization's website. The survey was sent to the panel organizations, and 10 complete responses from 10 organizations were received, plus 
three responses from two organizations with incomplete responses. We average the responses from the same organization as one.

All responding higher-education organizations (including incomplete responses from two organizations) indicate some level of social media presence. The structure of their social media programs usually includes some planning and/or evaluative processes, with 92\% structured with targeted audiences; 89\% with ways to measure social media results; 75\% with strategies; and $42 \%$ with clearly defined goals and measurable objectives. All organizations use multiple social media platforms, averaging 4.2 platforms. Similar as transit agencies and healthcare organizations, Facebook, Twitter and YouTube are the most commonly used social media, with $100 \%, 92 \%$ and $83 \%$ of the agencies using each of these three platforms, respectively. In addition, 75\% of the respondents use Instagram, 33\% of them use Pinterest, and a handful of agencies indicate usage of Snapchat, Storify, and Tumblr, etc.

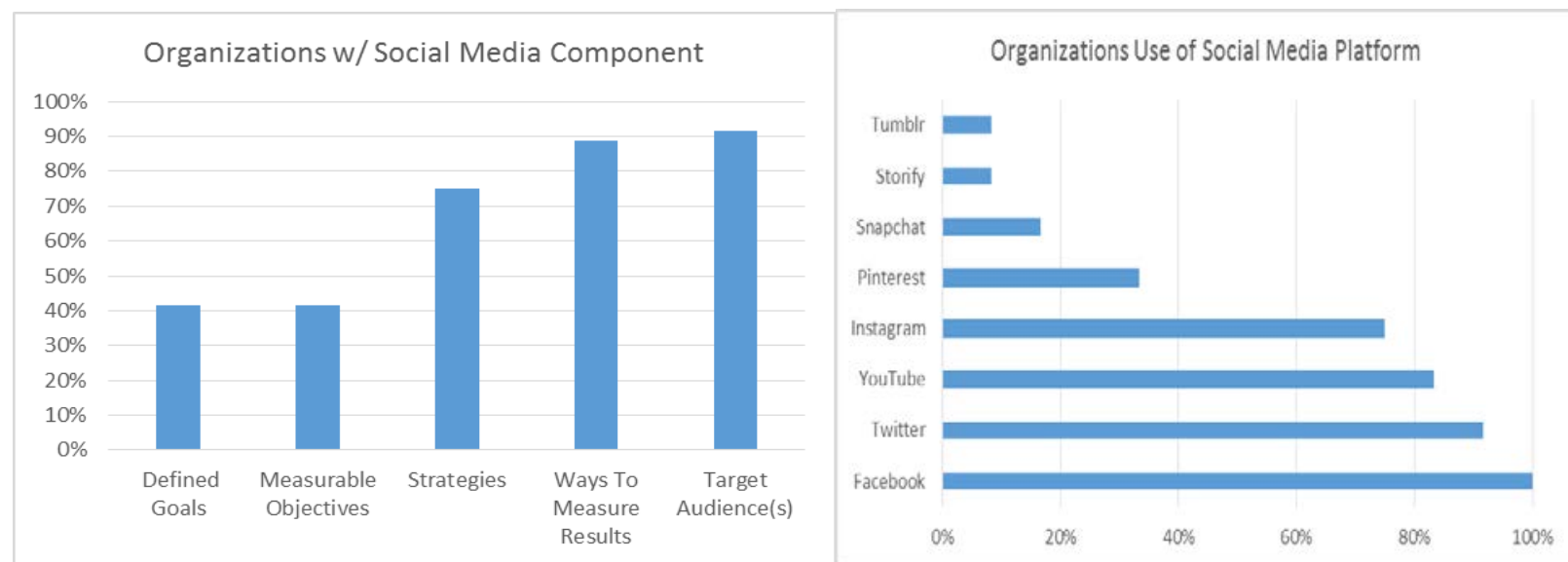

Figure 8. Social Media Program Components and Platforms

In terms of staff resources invested in social media, most agencies (including incomplete responses from two organizations) have multiple staff members working on their social media programs. Almost half of responding higher-education organizations have full-time staff exclusively dedicated to social media work. Nearly all organizations have multiple staff, even from different departments, responsible for social media, averaging around five employees

We found that higher-education organizations most frequently use social media to announce campus updates and events, as shown in Figure 8. They also frequently use social media to advocate school spirit promotions, share faculty and students profiles or stories, and spread a positive reputation of higher education. Some of them announce scholarship opportunities and information of school programs and degrees, but they consider these infrequently used themes as almost as valuable as other purposes mentioned above.

In terms of performance metrics, the most common measures among higher-education organizations are collecting numbers of subscribers and engagement activities through social 
media, such as replies, downloads, posts, etc. Some of them utilize positive reactions and perception from users, such as indications of attending events, perception of education as valuable, and messaging positive tones. However, they consider these reactions and perception indicators as important as the number of subscribers and activities, even though they are not frequently used.

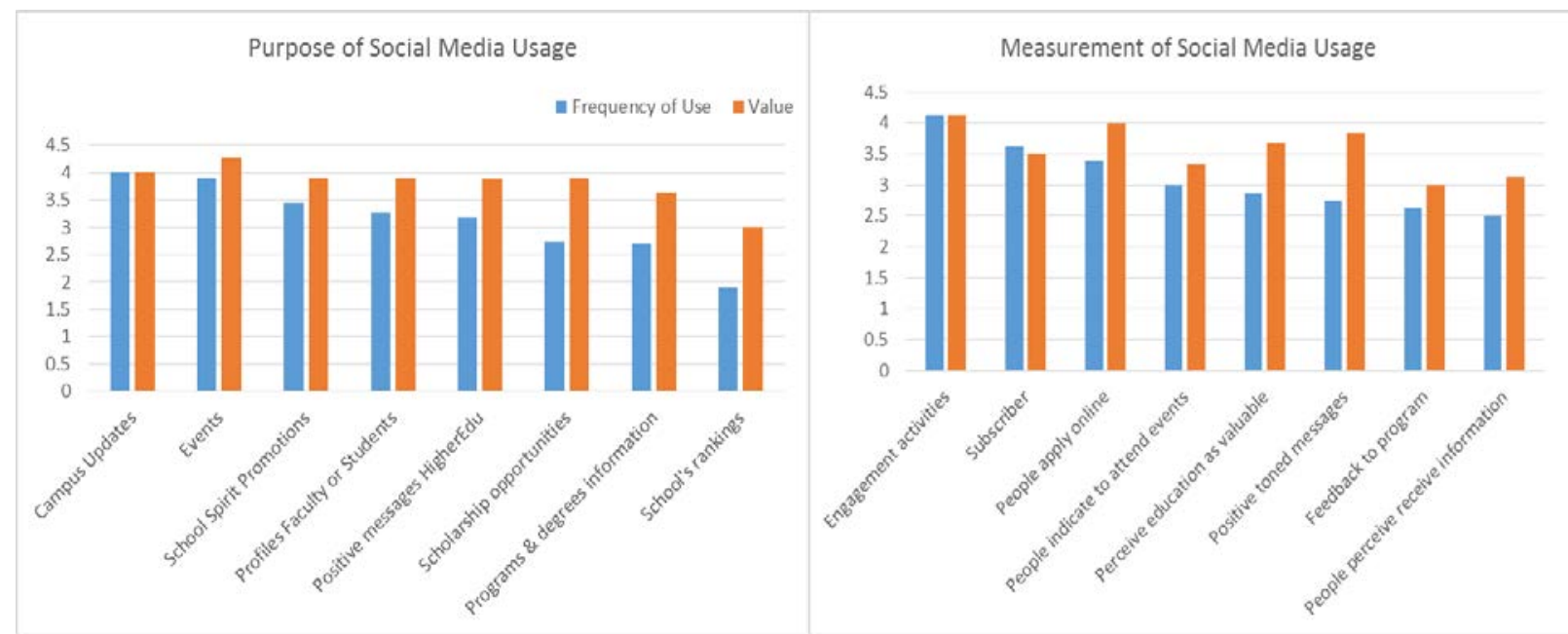

Figure 9. Purpose and Measurement of Social Media Usage in Healthcare Organizations

\subsection{SURVEY SUMMARY}

The potential benefits of social media drive agencies or organizations from different sectors to put great efforts to develop their social media programs. From the survey response results, we can conclude that all three different sectors apply multiple platforms to reach diverse groups and for different communication purposes. At the same time, these agencies or organizations devote considerable staff resources into social media management and development.

To be specific, transit agencies use social media for a variety of purposes: to communicate timely service information and get feedback and response comments are the most frequently used purposes. However, they consider transit-related livability and sustainability promotions to be valuable to communicate through social media program as well. In terms of healthcare and higher-education organizations, besides routine communication purposes of social media usage, some of them indicated the importance of building community connection and market promotion through social media.

Although agencies and organizations allocate many resources and efforts on social media program development, they lack professional performance metrics to fully understand the efficiency and broad benefits social media programs bring about. The most common measures they use are simply counting social media subscriber levels or engagement activities. Some organizations exploit more advanced metrics, such as sentimental analysis, to understand the perception of the organizations and their services, which go beyond simple data collection. Therefore, all agencies and organizations in the three sectors call for comprehensive performance 
metrics to fully capture activities and influence of their social media program. The potential performance metrics the surveyed agencies and organizations assert include: comprehensive metrics; holistic web traffic tracking; quality of social media messages; integration of efforts from multiple departments (i.e., marketing, communication, etc.); return on investment; costeffective tools; and constant reexamination, etc. 


\subsection{CASE STUDY}

We investigated social media usage among top transit agencies based on NTD database transit profiles, which rank agencies based on unlinked passenger trips. Fifty-one agencies in total were included, which are top 50 in 2012 and 2013 (one agency that was part of the list in 2012 was not part of the 2013 list). The geographical distribution of researched agencies is shown in Figure 10, plus the transit agencies in Puerto Rico and Honolulu.

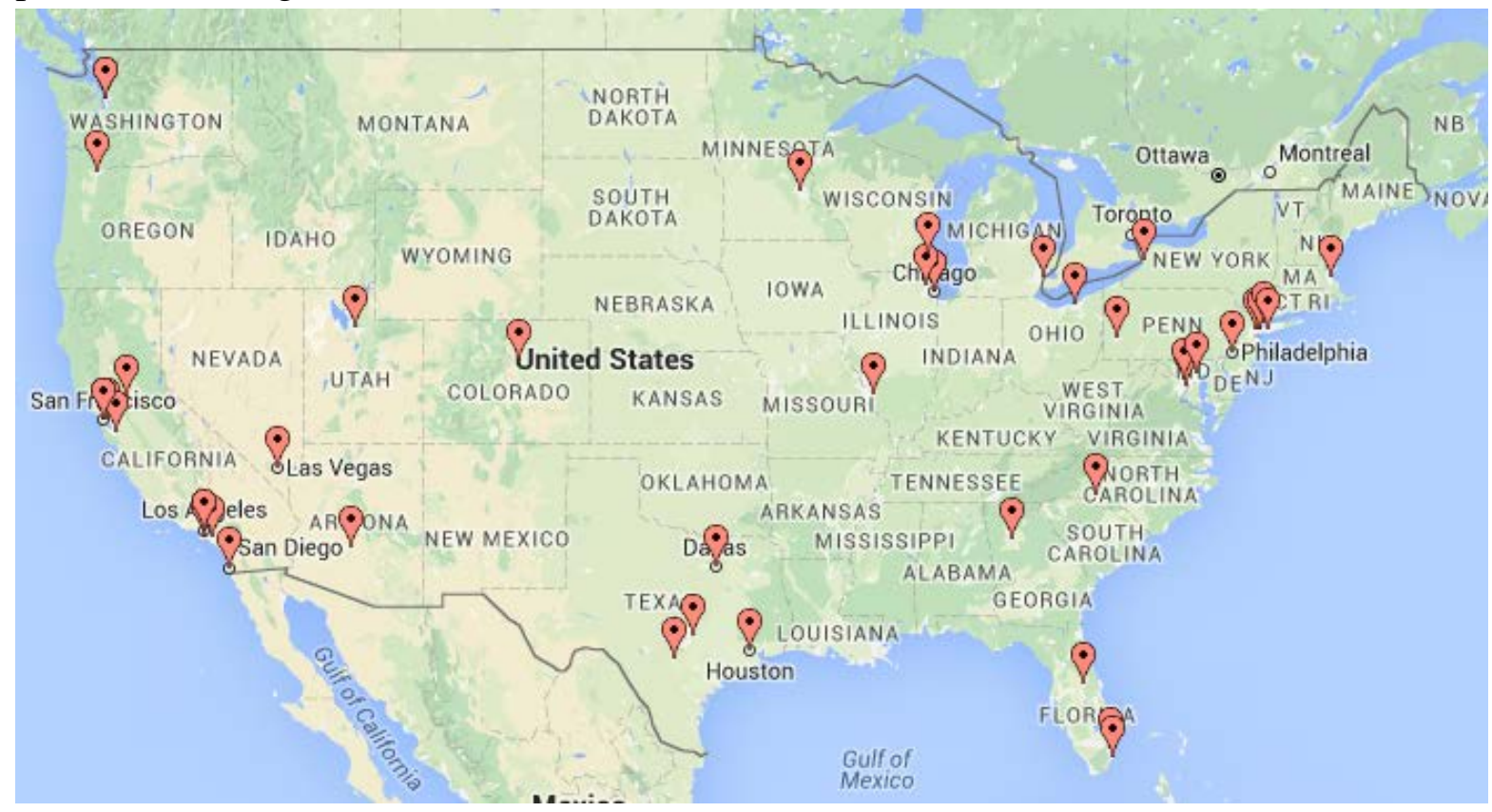

\section{Figure 10. Distribution of Researched Top Transit Agencies}

We conducted a comprehensive internet search about each agency's social media presence; policy description; incorporation with other agency plans (i.e., strategic plan, communications plan, public participation/involvement plan, and marketing plan); performance measurement; and unique experiences. As summarized in Table 4, almost all agencies have links to their social media interfaces on their official website (as linked social media icons), either on their homepages or within the social media section of their websites. However, only some of the agencies have explicated their social media contents, variation of different platforms and focus in an elaborate way. In terms of social media policy, there is a great deal of variation among agencies. Some of them only publish comments, policy or code of conduct to illustrate the basic rules of conducting social media work, while some but a limited number of agencies have elaborate goals, objectives, strategies, and detailed guidelines of developing the social media professions. Some agencies (i.e., departments of transportation), which may be governed on a 
municipal or county level, simply follow the social media strategies and action plans of the governing level of government.

In addition, social media plays an important role in agencies’ communication, public participation and marketing development. Although there is no specific social media plan in all of the agencies, they incorporate social media in other related plans, including public involvement, communications, strategic and marketing plans. They intend to consider social media as an important tool and technique to effectively communicate with users, involve the public, and even for digital marketing and branding.

Table 4. List of Top Transit Agencies' Social Media Presence on Official Website (as of May, 2016)

\begin{tabular}{|c|c|c|c|c|c|}
\hline$\#$ & Agency Name & City & State & $\begin{array}{l}\text { Social Media } \\
\text { on Website }\end{array}$ & $\begin{array}{l}\text { Incorporation with } \\
\text { other Plans }\end{array}$ \\
\hline 1 & $\begin{array}{l}\text { Alameda-Contra Costa Transit } \\
\text { District }\end{array}$ & Oakland & CA & & \\
\hline 2 & $\begin{array}{l}\text { Broward County Transit } \\
\text { Division }\end{array}$ & Plantation & FL & & Public Involvement Plan \\
\hline 3 & Capital Metro & Austin & TX & & $\begin{array}{l}\text { Strategic Plan; } \\
\text { Communication Plan }\end{array}$ \\
\hline 4 & $\begin{array}{l}\text { Central Florida Regional } \\
\text { Transportation Authority }\end{array}$ & Orlando & FL & & \\
\hline 5 & $\begin{array}{l}\text { Central Puget Sound Regional } \\
\text { Transit Authority }\end{array}$ & Seattle & WA & & Coordination Plan \\
\hline 6 & Charlotte Area Transit System & Charlotte & NC & & \\
\hline 7 & Chicago Transit Authority & Chicago & IL & & \\
\hline 8 & $\begin{array}{l}\text { City and County of Honolulu } \\
\text { Department of Transportation } \\
\text { Service }\end{array}$ & Honolulu & $\mathrm{HI}$ & & \\
\hline 9 & $\begin{array}{l}\text { City of Detroit Department of } \\
\text { Transportation }\end{array}$ & Detroit & MI & & $\begin{array}{l}\text { Public Participation \& } \\
\text { Involvement Plan }\end{array}$ \\
\hline 10 & $\begin{array}{l}\text { City of Los Angeles } \\
\text { Department of Transportation }\end{array}$ & $\begin{array}{l}\text { Los } \\
\text { Angeles }\end{array}$ & CA & & \\
\hline 11 & Dallas Area Rapid Transit & Dallas & TX & (1) 包 & Strategic Plan \\
\hline 12 & $\begin{array}{l}\text { Denver Regional } \\
\text { Transportation District }\end{array}$ & Denver & $\mathrm{CO}$ & & \\
\hline 13 & $\begin{array}{l}\text { Great Cleveland Regional } \\
\text { Transit Authority }\end{array}$ & Cleveland & $\mathrm{OH}$ & 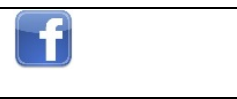 & \\
\hline 14 & $\begin{array}{l}\text { King County Department of } \\
\text { Transportation - Metro Transit } \\
\text { Division }\end{array}$ & Seattle & WA & & \\
\hline 15 & Long Beach Transit & $\begin{array}{l}\text { Long } \\
\text { Beach }\end{array}$ & CA & 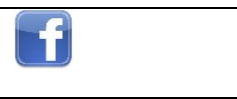 & \\
\hline 16 & $\begin{array}{l}\text { Los Angeles County } \\
\text { Metropolitan Transportation } \\
\text { Authority }\end{array}$ & $\begin{array}{l}\text { Los } \\
\text { Angeles }\end{array}$ & CA & & Public Participation Plan \\
\hline
\end{tabular}




\begin{tabular}{|c|c|c|c|c|c|}
\hline 17 & $\begin{array}{l}\text { Maryland Transit } \\
\text { Administration }\end{array}$ & Baltimore & MD & 1 & $\begin{array}{l}\text { Title VI Implementation } \\
\text { Plan }\end{array}$ \\
\hline 18 & $\begin{array}{l}\text { Massachusetts Bay } \\
\text { Transportation Authority }\end{array}$ & Boston & MA & 1 & Public Participation Plan \\
\hline 19 & Metra Commuter Rail & Chicago & IL & A & $\begin{array}{l}\text { Strategic Plan; } \\
\text { Marketing Plan }\end{array}$ \\
\hline 20 & Metro Transit (Minnesota) & $\begin{array}{l}\text { Minneapo } \\
\text { lis }\end{array}$ & $\mathrm{MN}$ & 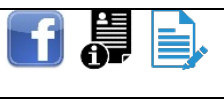 & \\
\hline 21 & $\begin{array}{l}\text { Metropolitan Atlanta Rapid } \\
\text { Transit Authority }\end{array}$ & Atlanta & GA & & \\
\hline 22 & $\begin{array}{l}\text { Metropolitan Transit Authority } \\
\text { of Harris County, Texas }\end{array}$ & Houston & TX & & \\
\hline 23 & Miami-Dade Transit & Miami & FL & (1) & Public Participation Plan \\
\hline 24 & $\begin{array}{l}\text { Milwaukee County Transit } \\
\text { System }\end{array}$ & $\begin{array}{l}\text { Milwauke } \\
\text { e }\end{array}$ & WI & & \\
\hline 25 & Montgomery County Transit & Rockville & MD & 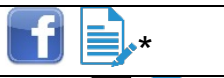 & \\
\hline 26 & MTA Bus Company & New York & NY & 翼豆。 & \\
\hline 27 & MTA Long Island Rail Road & New York & NY & & \\
\hline 28 & MTA Metro North Railroad & New York & NY & & \\
\hline 29 & MTA New York City Transit & New York & NY & & Digital Marketing Plan \\
\hline 30 & Nassau Inter County Express & $\begin{array}{l}\text { Garden } \\
\text { City }\end{array}$ & NY & & \\
\hline 31 & New Jersey Transit Corporation & Newark & NJ & i毁至。 & \\
\hline 32 & $\begin{array}{l}\text { Niagara Frontier Transportation } \\
\text { Authority }\end{array}$ & Buffalo & NY & & \\
\hline 33 & $\begin{array}{l}\text { Orange County Transportation } \\
\text { Authority }\end{array}$ & Orange & CA & is & \\
\hline 34 & Pace - Suburban Bus Division & $\begin{array}{l}\text { Arlington } \\
\text { Heights }\end{array}$ & IL & & \\
\hline 35 & $\begin{array}{l}\text { Port Authority of Allegheny } \\
\text { County }\end{array}$ & Pittsburgh & $\mathrm{PA}$ & & \\
\hline 36 & $\begin{array}{l}\text { Port Authority Trans-Hudson } \\
\text { Corporation }\end{array}$ & $\begin{array}{l}\text { Jersey } \\
\text { City }\end{array}$ & NJ & & \\
\hline 37 & $\begin{array}{l}\text { Puerto Rico Highway and } \\
\text { Transportation Authority }\end{array}$ & San Juan & PR & & \\
\hline 38 & $\begin{array}{l}\text { Regional Transportation } \\
\text { Commission of Southern } \\
\text { Nevada }\end{array}$ & Las Vegas & NV & (1) & Public Participation Plan \\
\hline 39 & $\begin{array}{l}\text { Sacramento Regional Transit } \\
\text { District }\end{array}$ & $\begin{array}{l}\text { Sacrament } \\
\text { o }\end{array}$ & CA & 9 & Strategic Plan \\
\hline 40 & $\begin{array}{l}\text { San Diego Metropolitan Transit } \\
\text { System }\end{array}$ & San Diego & CA & 9 & \\
\hline 41 & $\begin{array}{l}\text { San Francisco Bay Area Rapid } \\
\text { Transit District }\end{array}$ & $\begin{array}{l}\text { San } \\
\text { Francisco }\end{array}$ & CA & A & \\
\hline 42 & $\begin{array}{l}\text { San Francisco Municipal } \\
\text { Transportation Agency }\end{array}$ & $\begin{array}{l}\text { San } \\
\text { Francisco }\end{array}$ & CA & 1 & $\begin{array}{l}\text { Strategic Plan; } \\
\text { Public Participation } \\
\text { Plan; } \\
\text { Climate Action Strategy }\end{array}$ \\
\hline
\end{tabular}




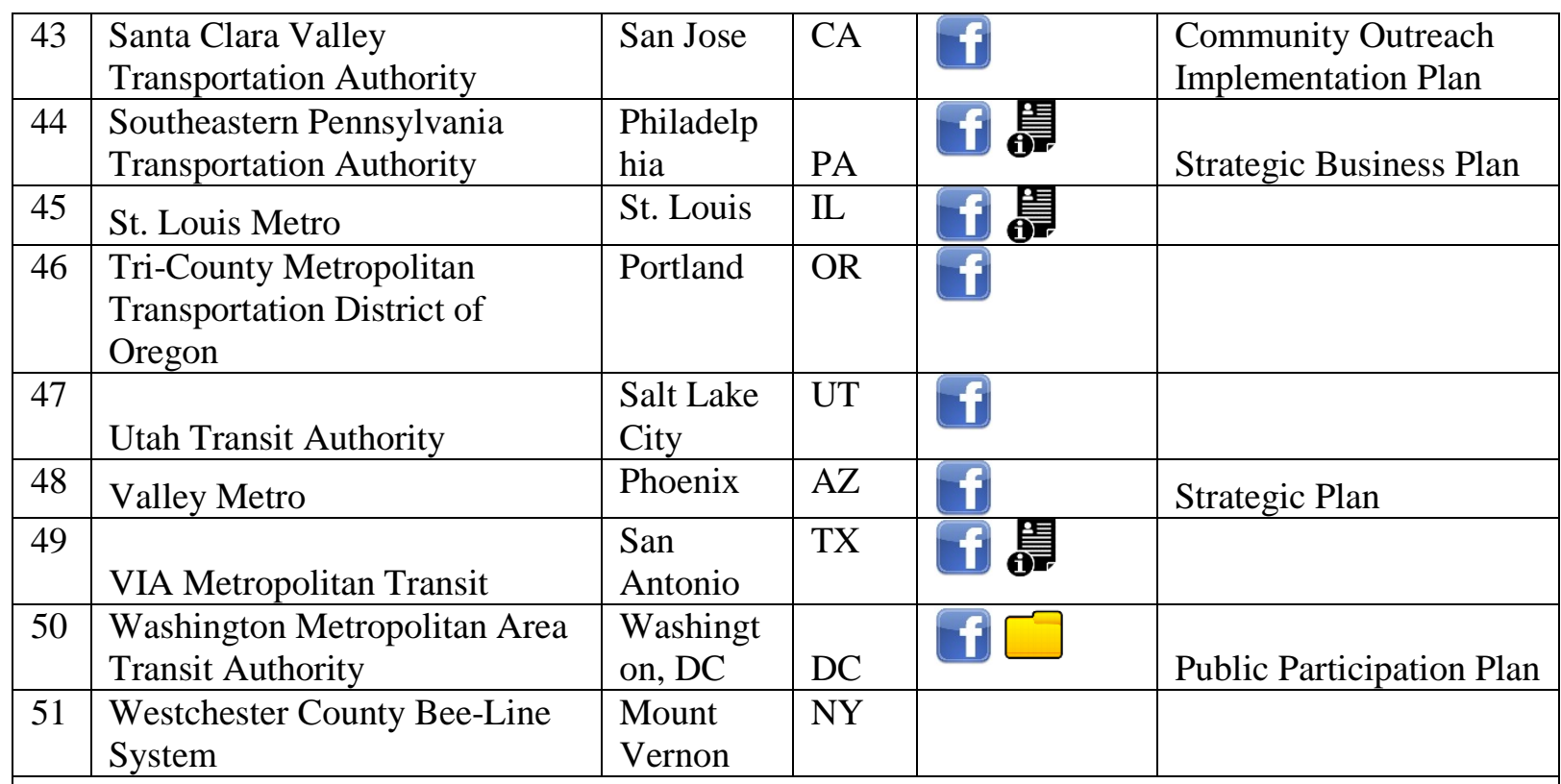

Notes:

- There are social media icons on the official website directly linking to their social media interfaces.

(1) - There is description of different social media platform profiles, contents, focus, etc.

豆 - There is simplified social media policy available, such as comment policy, code of conduct, etc.

- There is comprehensive social media policy available, including goal of usage, guidelines, action plans, etc.

The icons with an asterisk (莑, or $\square$ ) denote either a simplified or comprehensive social media policy that is not specific to the transit agency, but is part of the governing jurisdiction.

Most agencies present their social media interface icons on the front page or on a specific section on their official website, with concise description about contents of each social media channel. In general, Facebook and Twitter are both used for transit information updates and event announcements. Facebook also focuses on storytelling that positions agencies as part of the community, and Twitter is rider-focused. Some other platforms have their own focus as well; Instagram and Flickr are image-focused, LinkedIn is professional-focused, etc.

In the survey, over half of the responding agencies stated they have social media development guidelines, such as goals, objectives, strategies, measurable objectives and a target audience. However, there are a limited number of agencies that will present their social media strategies and policies on their website. Some of them just present comment policies or conduct of code in the social media policy section without elaboration on how they use these media and development concerns. 
Some of the good examples of social policy presentation include Central Puget Sound Regional Transit Authority (Sound Transit); Central Florida Regional Transportation Authority (LYNX); Washington Metropolitan Area Transit Authority (WMATA); and Miami-Dade Transit, among others. The common strengths in these agencies' social media policies are that they clarify their goals and objectives, provide strategies to conduct social media work besides comment policy, and even elaborate with detailed guidelines for term of use. In Sound Transit, they clearly define that the goal of social media includes growing agency awareness, enhancing communication of the agency's mission; providing timely rider feedback; and activating community interaction. Based on these goals, they elaborate on employee guidelines for conducting social media communication, and distinguish the content and audience focus of each social media channel. LYNX has its external social media policy for users published on its official website. It states that the purpose of social media is to encourage community interaction in dialog, and present public record policy and comment policy to users as well. Detailed scope and the audience of each social media channel are also illustrated in the social media policy document. Similarly, WMATA presents a separate file of social media terms of use to describe intent of use, public record and comment policy. Miami Dade provides detailed graphic and editorial standards for social media posting to guide its employees. 

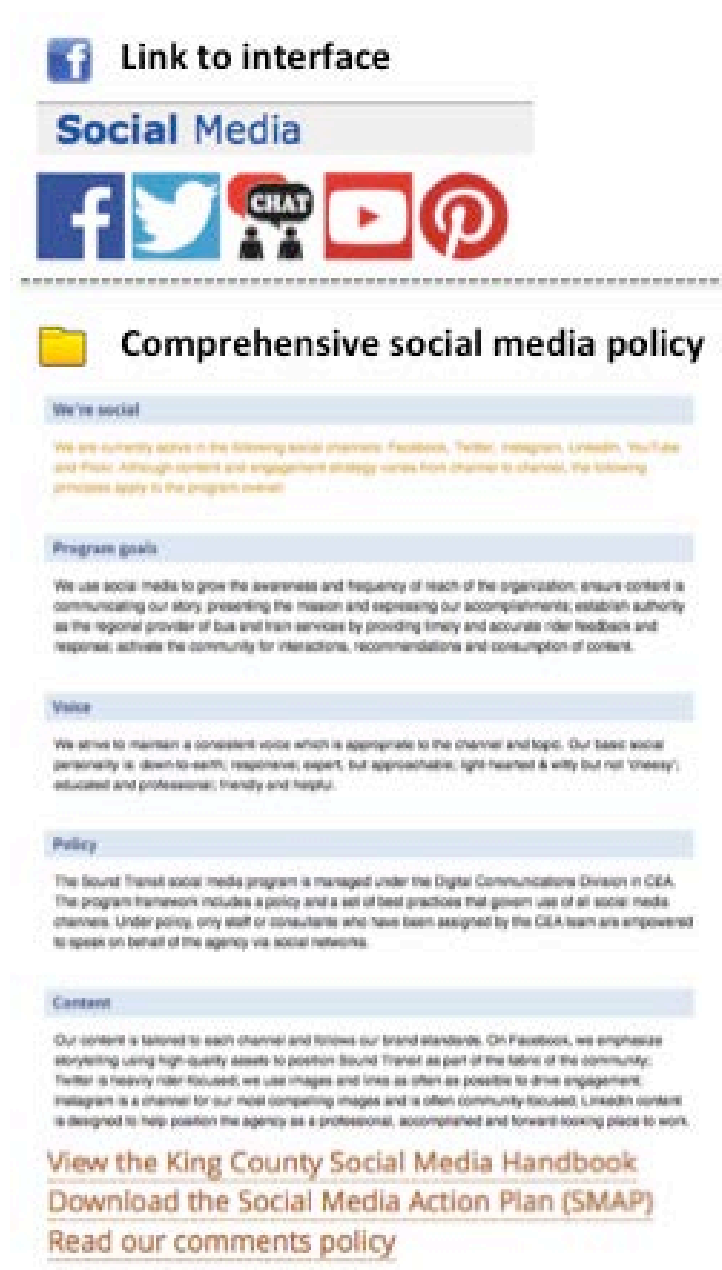

\section{Description of platform profiles}

Facebook

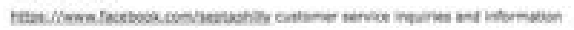

Twater

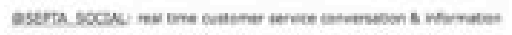

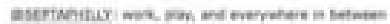

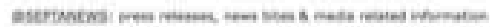

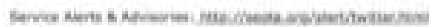

Instagram

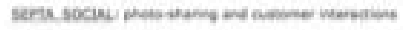

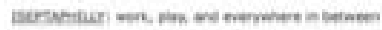

Tumbir

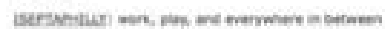

\section{Simplified social media policy}

\section{SOCIAL MEDIA COMMENT POLICY}

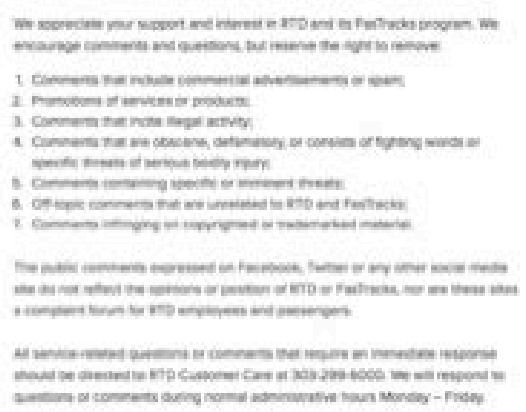

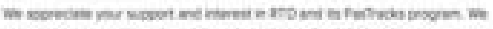

w new nom

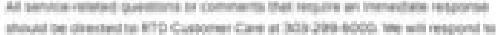

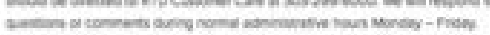

\section{Figure 11. Examples of Social Media Presence Notation}

Figure 12 is a word cloud of social media policy for four agencies mentioned above. Word clouds are visualizations based on a word frequency analysis of the text. In our case, each agency word cloud reflects the content focus of their policies. Besides common words such as "social," "media," and the name of the transit agency that appears in high frequency, we find different words are emphasized in different agencies, possibly indicating the direction of the policy emphasis. For example, Sound Transit considers social media as a channel of community engagement, which links to their social media development goal. LYNX and Miami Dade provide more guidelines for employees to compose posts and comments, and regulate the content and responsibilities of communication as well. WMATA simply provides guidance on the general purpose of use and presents a comments policy for its social media usage. 

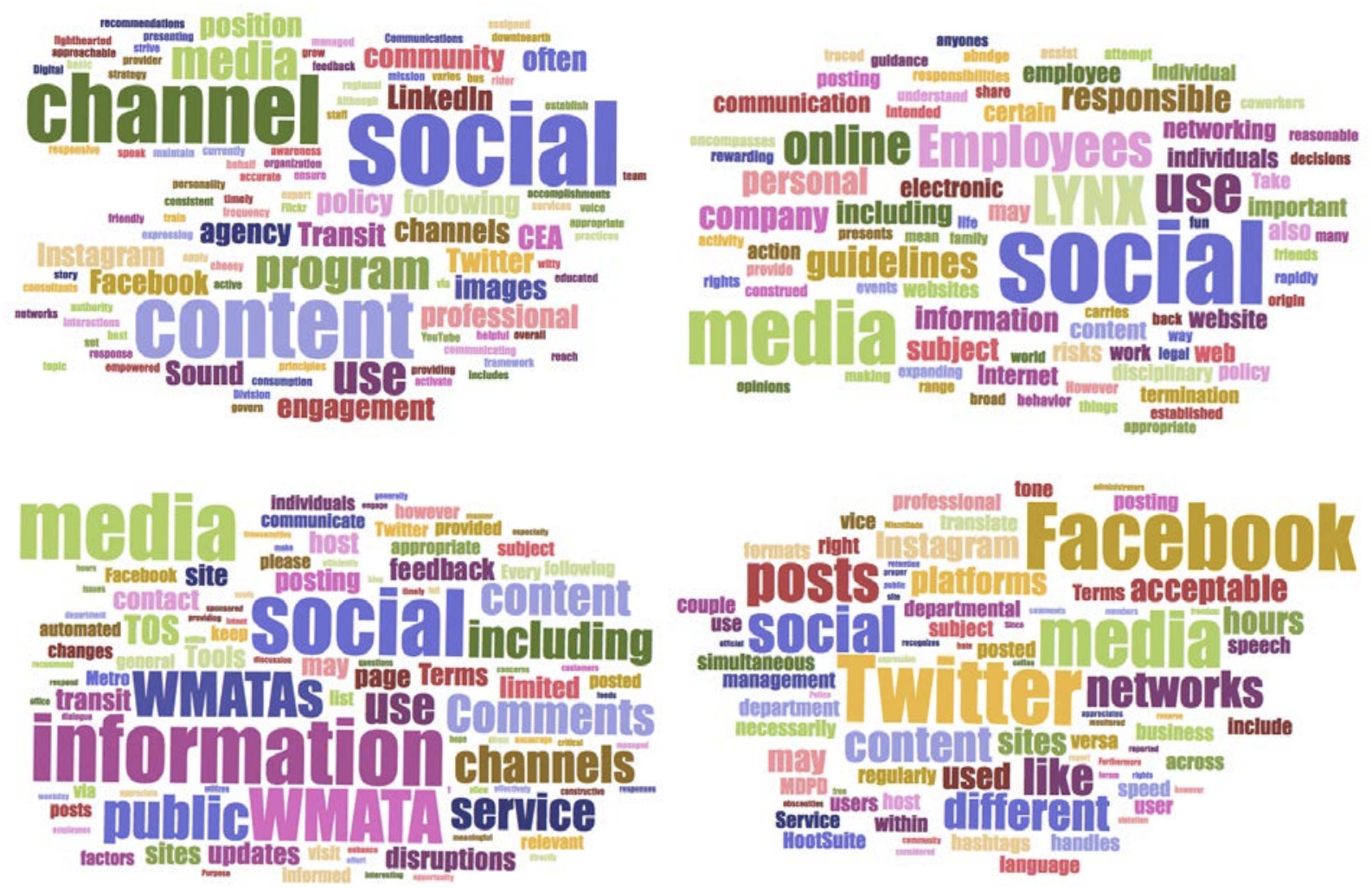

Figure 12. Word Cloud of Social Media Policy (Upper left: Sound Transit; Upper right: LYNX; Lower left: WMATA; Lower right: Miami Dade)

Although we did not find comprehensive transit agency-level social media plans in our case study research, we did find that many agencies include social media components into other plans, such as their strategic plan, communications plan, public participation/involvement plan, and marketing plan. Social media is considered an effective tool for achieving public participation and communications goals. Capital Metro in Austin incorporates social media in its strategic plan, and indicates the important role of social media strategies to improve customer service and branding. It also mentions social media in its communications and marketing plan, which considers social media as an important tool and method for communication. At the same time, they launched a social media strategy project, "Influence Opinions," to further investigate digital presence strategies for reaching minority groups, especially with limited English proficiency, given that almost half of Capital Metro's riders are Hispanic/Latino and African-American. Similarly, WMATA differentiates the role of social media to different groups of people in its participation plan. It indicates social media is appropriate for reaching young adults but not seniors and ethnic minorities such as the Hispanic population. Therefore, WMATA emphasizes focusing on different targeted populations in its social media content. In addition, MTA New York Transit elaborates on social media strategy in its digital marketing plan, which emphasizes the branding and engagement role of social media along with other digital strategies such as a website, mobile apps, etc. 
In terms of performance measures, a limited number of agencies have systematic tracking and analysis performance measures. Most of them track the descriptive statistics of followers, likes, and re-tweets, etc. For example, Southeastern Pennsylvania Transportation Authority (SEPTA) tracks social followers, likes, and activities in its customer service evaluation report. Maryland considers increases in re-tweets and re-posting as indications of success. Few agencies go beyond that based on our internet search. However, WMATA goes one step further to utilize customer relationship management (CRM) to evaluate its social media. It tries to integrate CRM to evaluate social media interaction through a resolution process. 


\subsection{PERFORMANCE METRICS}

\subsection{LESSONS FROM CURRENT SOCIAL MEDIA USAGE}

Social media still appears to be an emerging practice among transit agencies, where we find significant staff and resources are allocated to maintaining social media presence, but we also find a relative lack of structured goals and strategies for its development. Very few agencies possess clearly defined social media development guidelines, such as goals, objectives and strategies, according to the survey results and case studies. The ambiguity of social media goals and objectives prior to engagement in social media presents many uncertainties in its usage for transit agencies.

Based on our survey results, current social media performance metrics mainly focus on tracking social media subscriber numbers or the number of times that posts are circulated through the social media sphere (e.g., retweets or favorites). While most transit agencies indicate goals of increasing ridership and building livable communities through social media engagement, it is clear that the current set of performance measures does not directly correspond to and/or are not compatible with these goals. In addition, many agencies express high value in using social media as a reflection of public perception and satisfaction toward their agencies, and as a communication tool to convey the benefits of public transit (i.e., traffic relief, environmentfriendly, sustainable living, etc.). Very few agencies are able to track the effectiveness of their social media communications to these ends. More advanced social media performance metrics that measure perception and service satisfaction through techniques such as data mining and sentiment analysis have been utilized more frequently in other settings. Along with data-mining techniques for early traffic-incident detection and management of emergency events, these advanced data techniques may be incorporated into the development of performance metrics, depending on the specific goals and objectives of the social media program.

\subsection{RECOMMENDATIONS}

For public transit agencies, we recommend starting with the overarching mission statement of the agency, establishing social media program goals based on its mission and defining clear, specific and measurable objectives (or steps) to direct the social media program towards achieving these goals. Finally, we recommend developing social media performance metrics and data collection procedures that specifically capture the degree and the level of efficiency and effectiveness to which objectives are being achieved. 
As previous literature and survey results indicate, performance metrics developed with specific development goals and objectives prior to implementation are more likely to be useful (Bregman, 2012; Owyang \& Lovett, 2012). First, it is essential for the social media program to characterize and maintain its relevancy with regards to the overall mission of the transit agency and its purposes, operation objectives and priorities. Agency communication and marketing plans should also address the role of social media in achieving communications and marketing goals. With these clear social media development goals and objectives spelled out, program monitoring, measurement and data collection procedures can then be established accordingly within the framework.

Based on this research, we recommend a social media performance metric framework similar to the key performance indicators (KPIs) designed to evaluate social media programs in the healthcare sector (Neiger et al., 2012). This performance metric framework measures social media reach, insights, engagement and efficiency in the public transportation sector:

- Reach: This metric mainly measures the number of people who are engaged or who are interacting with the agency via social media programs. This is the most straightforward and most commonly collected metric.

- Insights: This metric emphasizes consumer or community perception and satisfaction toward transit service and the transit mode that are expressed through social media. Beyond simply collecting subscriber and re-post numbers, this metric focuses more on measuring the quality of social media messages and feedback loops.

- Engagement: This metric measures the culminating outcomes that link to actions, such as ridership increase, activity participation, and other measures that are central to transit agency missions and goals.

- Efficiency: This metric focuses on the cost-effectiveness aspect of social media usage, evaluating the return on investment for the benefits achieved above (including reach, insights, engagement, etc.) based on resources allocated toward these programs.

The comprehensive performance metrics framework is a combination of quantitative and qualitative analytics. The quantitative metrics provide straightforward indicators of program achievements, while the qualitative metrics measure the quality of interactions and engagement through stakeholder feedback and actions. All these advanced approaches are utilized to understand the quality of social media programs, and provide effective information to further enhance the social media program as an instrument in achieving the mission of public transit agencies. 


\subsection{CONCLUSION}

A growing number of public transportation agencies use social media programs to inform and engage communities. Public transit agencies are devoting significant efforts and resources towards social media programs to enable better communications to a broad audience. However, we find a relative lack of performance measures that can characterize the efficiency and effectiveness of social media programs. We also find missing linkages between these programs and transit agency missions, goals and objectives. Our project unfolds this question by reviewing the literature on social media usage in the transportation, healthcare and education sectors, surveying top transit agencies about their current social media usage and measurement, and conducting case study reviews of top agency websites.

We conducted an online survey of top transit agencies in the U.S., along with healthcare and higher-education organizations, to understand their usage of social media. We find transit agencies use social media mainly to communicate timely service information and get feedback from customers through multiple platforms. In addition, agencies consider transit-related livability and sustainability benefits to be valuable information to communicate through social media. Although wide usage of various social media platforms was observed across agencies, a general lack of consistent performance metrics was also observed. Many agencies are limited to simple counts of social media subscribers or followers, or re-posting/liking activities, without additional analysis of the quality or interaction of social media messages. More advanced techniques and metrics, such as text mining and sentiment analysis, may be necessary to better characterize social media program performance depending on specific agency goals and objectives.

In addition, we conducted a case study assessment of top transit agencies' social media presence, social media documents and policy descriptions, and performance measurements (if available). Most agencies link to the various social media platform profiles through their websites, but we find that few have program documents or policy guidance that deal with social media content, usage or other related materials. The available documentation shows that social media is indeed playing an important role in how public transit agencies communicate, encourage public participation and market their services. However, consistent with our survey results and literature review, performance metrics for social media programs are still limited and insufficient.

Finally, we propose a conceptual performance metrics framework to develop constructive social media program metrics that focus on reach, insights, engagement and efficiency going forward. As a combination of quantitative and qualitative data, this framework will work best when it is strongly connected with a public transit agency's mission, goals and objectives associated with social media programs. 


\subsection{REFERENCES}

Bartlett, J., \& Miller, C. (2013). The State of The Art: A Literature Review of Social Media Intelligence Capabilities for Counter-Terrorism. No. November. Retrieved from https://www.publicsafety.gc.ca/lbrr/archives/cn28613-eng.pdf

Bregman, S. (2012). Uses of social media in public transportation. Transportation Research Board.

Brenner, J., \& Smith, A. W. (2013). 72\% of Online Adults are Social Networking Site Users. Retrieved from http://www.pewinternet.org/2013/08/05/72-of-online-adults-are-socialnetworking-site-users/

Bretschneider, S., \& Mergel, I. (2010). Techonology and Public Management Information System: Where have we been and where are we going. In D. Menzel \& H. White (Eds.), The State of Public Administration: Issues, Challenges, and Opportunities (pp. 187-203). New York: M.E. Sharpe Inc.

Chin, D., Choy, M., Ciavarella, L., Cosgriff, C., Popovich, J., \& Stenoien, D. (2012). Harnessing the Power of Social Media.pdf. Retrieved from http://www.apta.com/mc/annual/previous/2012/presentations/Presentations/Team-ThreeSocial-Media-Final\%20Report.pdf

Chou, W., Hunt, Y., Beckjord, E., Moser, R., \& Hesse, B. (2009). Social Media Use in United States: Implication for Health Communication. Journal of Medicine Internet Research, 11(4), e48. https://doi.org/10.2196/jmir.1249

Collins, C., Hasan, S., \& Ukkusuri, S. V. (2013). A novel transit rider satisfaction metric: Rider sentiments measured from online social media data. Journal of Public Transportation, 16(2), 2.

Congeni, L., \& Underwood, S. (2013). Healthy Conversation: Benchmarking the Social Media of America’s Top 15 Health Systems. Retrieved from http://healthcareleadership.bob.tv/wpcontent/uploads/sites/10/2014/12/Marilyn_Canna-social-top-15-health-systems.pdf 
Correa, T., Hinsley, A. W., \& de Zúñiga, H. G. (2010). Who interacts on the Web?: The intersection of users' personality and social media use. Computers in Human Behavior, 26(2), 247-253. https://doi.org/10.1016/j.chb.2009.09.003

CSC. (2012). Should Healthcare Organizations Use Social Media? A Global Update. Retrieved from http://assets1.csc.com/health_services/downloads/CSC_Should_Healthcare_Organization s_Use_Social_Media_A_Global_Update.pdf

Duggan, M., \& Brenner, J. (2013). The demographics of social media users - 2012 (Vol. 14). Pew Research Center’s Internet \& American Life Project Washington, DC. Retrieved from http://www.lateledipenelope.it/public/513cbff2daf54.pdf

Fyfe, T., \& Crookall, P. (2010). Social Media and Public Sector Policy Dilemmas.pdf. Retrieved from http://citeseerx.ist.psu.edu/viewdoc/summary?doi=10.1.1.472.1413

Galloway, S., \& Guthrie, D. (2010). Digital IQ Index: U.S. Senate. Retrieved from https://www.actiac.org/sites/default/files/senatedigitaliq.pdf

Godwin, B., Campbell, S., Levy, J., \& Bounds, J. (2008). Social media and the federal government: Perceived and real barriers and potential solutions. Federal Web Managers Council, 1-4.

Havard Business Review. (2010). The New Conversation: Taking Social Media from Talk to Action. Retrieved from http://www.sas.com/events/pbls/2010/lasvegas/documents/TheNewConversation.pdf

Hrdinova, J., Helbig, N., \& Peters, C. S. (2010). Designing social media policy for government: Eight essential elements. Center for Technology in Government, University at Albany. Retrieved from http://assembly.nu.ca/library/Edocs/2010/000957-e.pdf

Marshall, A. (2015, February). How Public Transit Agencies Deal with All Your Angry, Mean, and Terrible Tweets - CityLab.pdf. Retrieved from http://www.citylab.com/tech/2015/02/how-public-transit-agencies-deal-with-all-yourangry-mean-and-terrible-tweets/385373/

Mergel, I. (2012). Measuring the Impact of Social Media use in Public Sectors. In E. Downey \& M. Jones (Eds.), Public Service, Governance and Web 2.0 Technologies: Future Trends in Social Media (pp. 48-64). Hershey, PA: Information Science Reference.

NASCIO. (2010). A National Survey of Social Media Use in State Government. 
Neiger, B. L., Thackeray, R., Burton, S. H., Giraud-Carrier, C. G., \& Fagen, M. C. (2012).

Evaluating social media's capacity to develop engaged audiences in health promotion settings use of Twitter metrics as a case study. Health Promotion Practice, 1524839912469378.

Neiger, B. L., Thackeray, R., Burton, S. H., Thackeray, C. R., \& Reese, J. (2013). Use of Twitter among Local Helath Departments: An Analysis of Infromation Sharing, Engagement, and Action. Journal of Medicine Internet Research, 15(8), e177.

Neiger, B. L., Thackeray, R., Van Wagenen, S. A., Hanson, C. L., West, J. H., Barnes, M. D., \& Fagen, M. C. (2012). Use of social media in health promotion purposes, key performance indicators, and evaluation metrics. Health Promotion Practice, 13(2), 159-164.

Owyang, J., \& Lovett, J. (2012). Social marketing analytics.

Parveen, F., Jaafar, N. I., \& Ainin, S. (2015). Social media usage and organizational performance: Reflections of Malaysian social media managers. Telematics and Informatics, 32(1), 67-78. https://doi.org/10.1016/j.tele.2014.03.001

Pender, B., Currie, G., Delbosc, A., \& Shiwakoti, N. (2014). Social Media Use during Unplanned Transit Network Disruptions: A Review of Literature. Transport Reviews, 34(4), 501-521. https://doi.org/10.1080/01441647.2014.915442

Prensky, M. (2001). Digital natives, digital immigrants. On the Horizon, 9(5), 1-6.

Raymond, M., \& O’Hara, R. (2014). Communicating at the Speed of Light: Using Social Media as a Marketing Tool. In S. Bregman \& K. E. Watkins (Eds.), Best Practices for Transportation Agency Use of Social Media (1st ed.). New York: CRC Press.

Reform Support Network. (2013). Measurable Success, Growing Adoption, Vast Potential: Social Media Use among State and Local Education Agencies. Retrieved from http://www2.ed.gov/about/inits/ed/implementation-support-unit/tech-assist/social-mediause.pdf

Schweitzer, L. (2014). Planning and Social Media: A Case Study of Public Transit and Stigma on Twitter. Journal of the American Planning Association, 80(3), 218-238. https://doi.org/10.1080/01944363.2014.980439

Smith, A. W., Schlozman, K. L., Verba, S., \& Brady, H. (2009). The Internet and civic engagement. Pew Internet \& American Life Project Washington, DC. 
Thackeray, R., Neiger, B. L., Smith, A. K., \& Van Wagenen, S. B. (2012). Adoption and use of social media among public health departments. BMC Public Health, 12(1), 242. https://doi.org/10.1186/1471-2458-12-242

The Use of Social Media by Transportation Agencies. (2011). The Urban Transportation Monitor, 25(1), 18-25.

Wigand, D. (2012). Communication and Collaboration in a Web 2.0 World. In D. Menzel \& H. White (Eds.), The State of Public Administration: Issues, Challenges, and Opportunities (pp. 1-18). New York: M.E. Sharpe Inc. 


\title{
8.0 APPENDIX - SURVEY INSTRUMENT
}

\begin{abstract}
Hello and welcome!
In the age of smartphones and the internet, there is no doubt that Social Media is becoming increasingly popular, but is it being used efficiently? We are here to answer these related, but more specific questions such as how does social media help public transit agencies, what are the best practices, and how do we evaluate these methods? Your participation is very important in helping our team design a toolbox of metrics to capture the cost and benefits of Social Media programs in public transit agencies.
\end{abstract}

This survey is voluntary and will take about 15 minutes to complete. If you need to step away and are unable to complete the survey all at once, you will be able to return to complete it from where you left off. You may choose to refrain from participation at any point of this survey. Your non-participation will in no way, shape or form affect you or your job negatively.

The results of the project will be documented in a report which will be shared with all survey participants. Your input will be tremendously appreciated and will be kept strictly confidential. All personal identifiers will be removed prior to the sharing of findings.

Thank you very much for your valuable contributions.

By clicking on 'Next', you are consenting to participating in the survey and confirming that you are 18 years of age or older.

\section{$-$}

This survey is being conducted by Portland State University's (PSU) Toulan School of Urban Studies \& Planning (TSUSP), in partnership with the Center for Infrastructure, Transportation, and Envronment (CITE) at Rensselaer Poyytechnic institute. The Principal Investigator (PI) of this study is Dr. Jenny H. Liu, Assistant Professor at PSU TSUSP. This study was generously sponsored by the National Institute of Transportation and Communities (NITC). If you have any questions or technical difficultes, please contact Dr. Jenny Lu at 503-725-4049 or emai jenny.fugepdx.edu. Maling address: Portland State University Urban Studies \& Planning - College of Urban \& Public Affairs (USP), PO Box 751 Portland, OR 97207 .

Institutional Review Board approval was obtained from Karen Celarius, Human Subjects Research Review Committee (HSRRC) at PSU. If you have any questions for the Human Subjects Research Review Committee (HSRRC), their phone number is 503-725-2227 and address is Office of Research Integnity 1600 SW 4th Ave., Market Center Building Subjects Research Review Con
Sute 620 , Portland, OR 97201.

\begin{tabular}{|c|c|}
\hline \multicolumn{2}{|c|}{ Please confirm or enter your agency name: } \\
\hline Agency & $\$\{e \cdot / /$ Field/Agency\} \\
\hline \multicolumn{2}{|c|}{ Does your agency have a Social Media presence? } \\
\hline \multicolumn{2}{|l|}{ Yes } \\
\hline \multicolumn{2}{|l|}{ No } \\
\hline \multicolumn{2}{|c|}{ Oontact Info } \\
\hline \multicolumn{2}{|c|}{ Please confirm and/or provide some background information } \\
\hline Agency & \$(q://QID6 1/ChoiceTextEnt \\
\hline First Name & $\$\{e / /$ Field/FirstName\} \\
\hline
\end{tabular}


Position Title

Email

Phone number ( $x x x-x x x x-x x x x)$

Fax number $(x x x-x x x-x x x x)$
\$(e://Field/Title)

\$(e://Field/PrimaryEmail)

$\$[$ e:/Field/Phone $\}$

$\$(e \cdot /$ Field $/$ Fax $]$

No Social Media Presence

Thank you so much for taking time out to complete this survey. Please let us know below if you have any comments that you would like to communicate to the researchers.

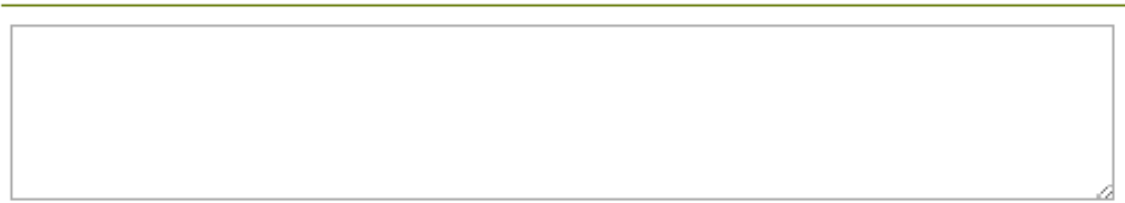

\section{Background}

\section{Let's start with some general information about your Social Media Program:}

Does your agency have a Social Media program with: (check all that apply)
$\square$ Clearly Defined Goals
$\square$ Strategies
$\square$ Measurable Objectives
Ways To Measure Results

$\square$ Target Audience(s)

Please answer the following question about your agency's goals and staff:

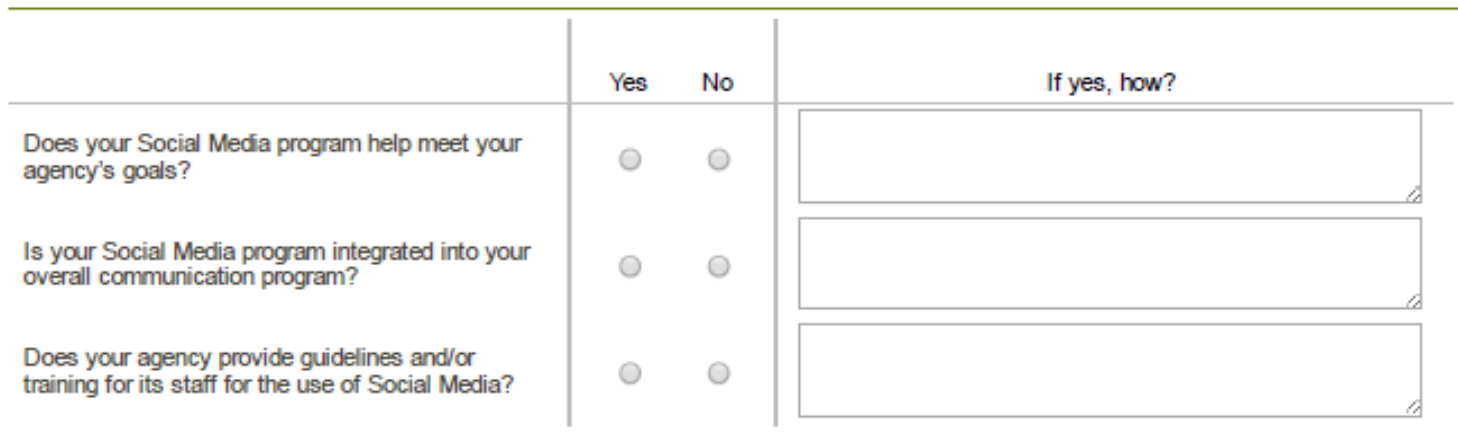

How many staff do you have for your social media program?

Full-Time staff exclusively dedicated to social media

Other staff with social media responsibilities

What Social Media Platform(s) do you use?
$\square$ Facebook
$\square$ Twitter
$\square$ YouTube

Instagram

$\square$ None
$\square$ Other


Types of Social Media Programs

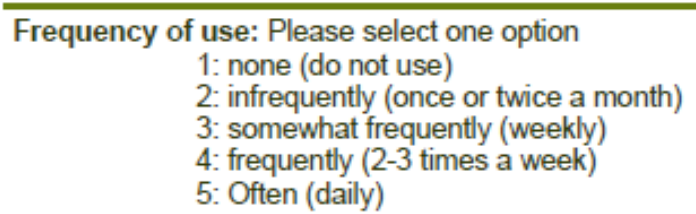

Value: Whether your agency uses each type of message or not, please provide the potential effectiveness and value of sending this type of communication through social media.

What do you talk about on social media? How often? How much value does each message have in achieving your goals?

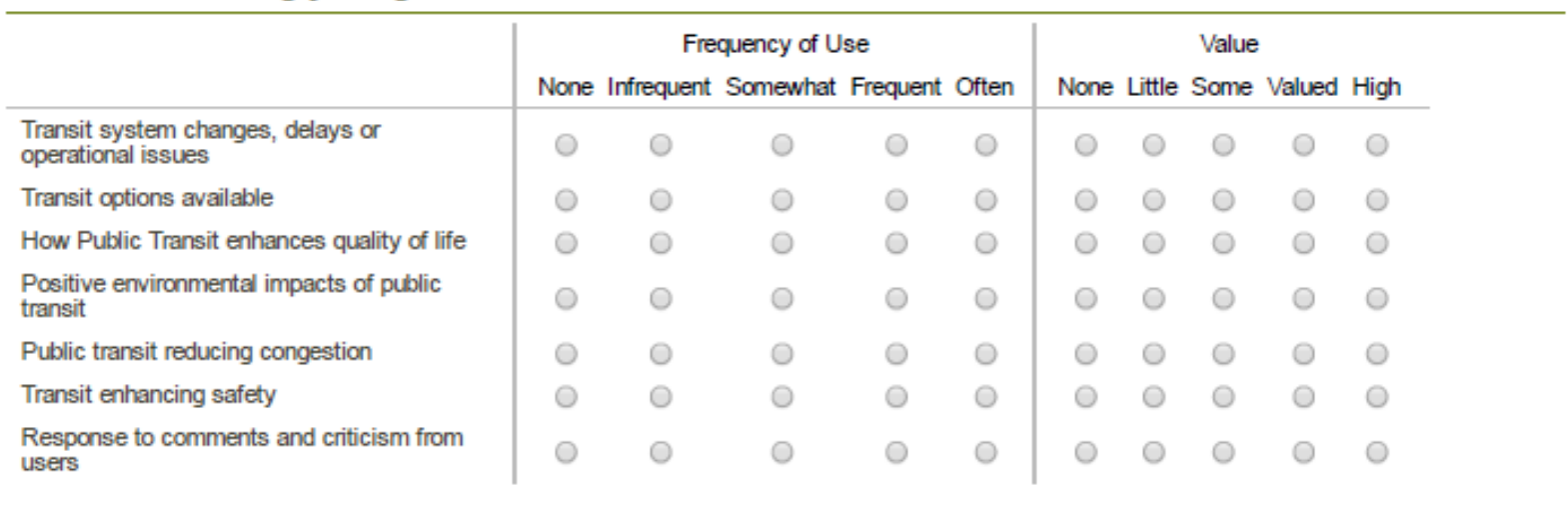

Comments

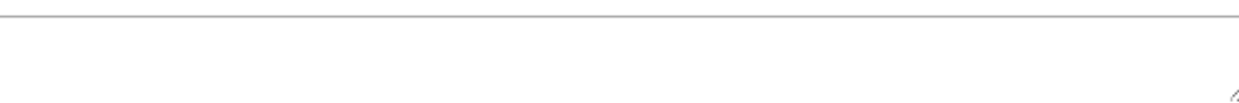

Measurement I: Output Measures

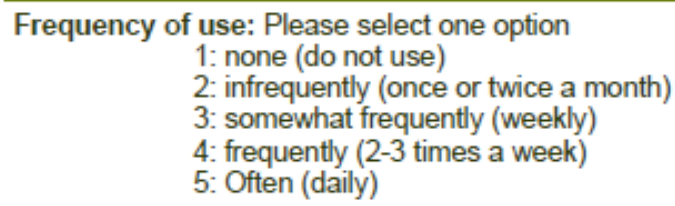

Value: Whether your agency uses each type of metric or not, please provide your opinion on the value of this type of metric in evaluating social media goals.

Now that we know what you talk about on social media, how often do you use the following metrics to measure your results? How much value does each measure provide in informing how well you are achieving your goals? 


\begin{tabular}{|c|c|c|c|c|c|c|c|c|c|c|}
\hline & \multicolumn{5}{|c|}{ Frequency of Use } & \multicolumn{5}{|c|}{ Value } \\
\hline & None & Infrequent & Somewhat & Frequent & Often & None & Little & Some & Valued & High \\
\hline $\begin{array}{l}\text { Number of people subscribed to your social } \\
\text { media }\end{array}$ & 0 & 0 & 0 & 0 & 0 & 0 & 0 & 0 & 0 & 0 \\
\hline $\begin{array}{l}\text { Number of people engaged through comments, } \\
\text { messages, document downloads, subscriptions, } \\
\text { feedback, posts, likes, etc. }\end{array}$ & 0 & 0 & 0 & 0 & $\bigcirc$ & $\odot$ & 0 & 0 & 0 & 0 \\
\hline $\begin{array}{l}\text { Number of people who indicate they received } \\
\text { real-time information about service options, } \\
\text { systems change and/or disruptions. }\end{array}$ & 0 & 0 & 0 & 0 & 0 & 0 & 0 & 0 & 0 & 0 \\
\hline $\begin{array}{l}\text { Number of people who perceive transit agencies } \\
\text { as reliable. }\end{array}$ & 0 & 0 & 0 & $\bigcirc$ & 0 & 0 & 0 & 0 & 0 & 0 \\
\hline $\begin{array}{l}\text { Number of people who perceive transit agencies } \\
\text { as environmentally-sensitive. }\end{array}$ & 0 & 0 & 0 & 0 & $\bigcirc$ & 0 & 0 & 0 & 0 & $\bigcirc$ \\
\hline $\begin{array}{l}\text { Number of people who indicate they intend to } \\
\text { rely more on transit for their future travel needs. }\end{array}$ & $\bigcirc$ & 0 & 0 & $\bigcirc$ & 0 & 0 & 0 & 0 & 0 & 0 \\
\hline $\begin{array}{l}\text { Number of people who provide feedback to } \\
\text { system changes or improvement. }\end{array}$ & 0 & 0 & 0 & 0 & 0 & 0 & 0 & 0 & 0 & 0 \\
\hline $\begin{array}{l}\text { Number of positive toned messages related to } \\
\text { your agency on social media. }\end{array}$ & 0 & 0 & 0 & 0 & 0 & $\bigcirc$ & 0 & $\bigcirc$ & 0 & $\bigcirc$ \\
\hline
\end{tabular}

Comments:

We're almost done! Do you have any recommendations for...

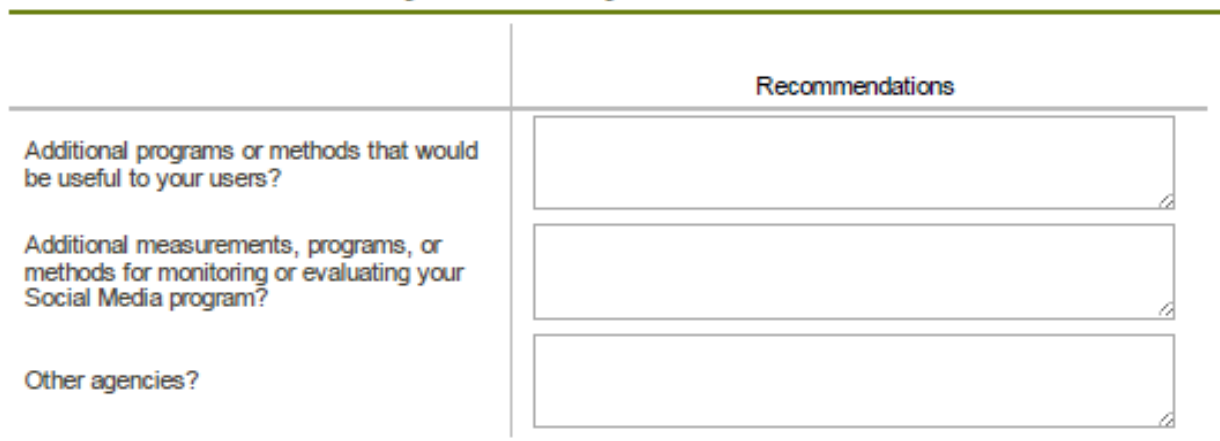

Do you have any other comments to help us understand how your agency evaluates your Social Media Program?

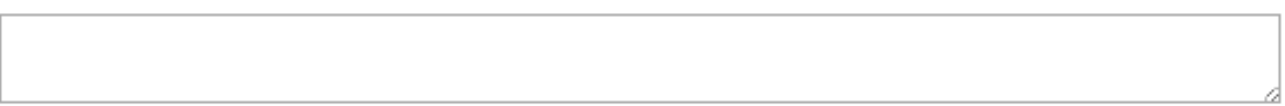

Would you be willing to receive follow-up communications (email or phone call) from the research team if we have any questions regarding your responses or to further discuss your social media program?
Yes
No 
Transportation Research and Education Center

Portland State University

1900 S.W. Fourth Ave., Suite 175

Portland, OR 97201 